

\section{DISCLAIMER}

This report was prepared as an account of work sponsored by an agency of the United States Government. Neither the United States Government nor any agency Thereof, nor any of their employees, makes any warranty, express or implied, or assumes any legal liability or responsibility for the accuracy, completeness, or usefulness of any information, apparatus, product, or process disclosed, or represents that its use would not infringe privately owned rights. Reference herein to any specific commercial product, process, or service by trade name, trademark, manufacturer, or otherwise does not necessarily constitute or imply its endorsement, recommendation, or favoring by the United States Government or any agency thereof. The views and opinions of authors expressed herein do not necessarily state or reflect those of the United States Government or any agency thereof. 


\section{DISCLAIMER}

Portions of this document may be illegible in electronic image products. Images are produced from the best available original document. 
MLM- 2108

TID -4500

UC -4

\title{
Topics in Aqueous Plutonium Chemistry
}

\author{
G. L. Silver
}

Issued: March 15, 1974

\section{NOTICE}

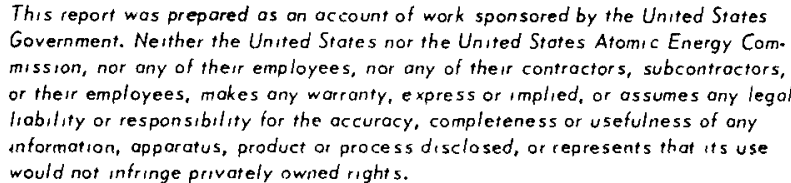

This report was prepared as an account of wark sponsored by the Unuted States Government. Neither the United States nor the Unired States Atomic Energy Commission, nor any of their employees, nor any of their contractors, subcontractors, or thesr employees, makes any warranty, express or implied, or assumes any legal liabilify or responsibility for the accuracy, completeness or usefulness of any information, apparatus, product at process disclosed, ar represents that it s use would not infringe peivately owred rights.

PRINTED IN THE UNITED STATES OF AMERICA Avalable from

National Technical Information Service

U S Department of Commerce

5285 Port Royol Rocrd

Springfield Virginia 2215

Price Printed Copy $\$ 400$, Microfiche $\$ 145$

MONSANTO RESEARCH CORPORATION

A Subsidiary of Monsanto Company

MOUND LABORATORY

Miamisburg, Ohıo

45342

operated for

\section{UNITED STATES ATOMIC ENERGY COMMISSION}

U S Government Contract No AT-33-1-GEN-53 


\begin{abstract}
The general plutonium equilibrium problem is solved with logarithms and a logarithmic form of the plutonium characteristic equation is suggested. Other topics include numerical methods for estimating the equilibrium acidity in plutonium solutions, a characteristic equation for the iron-plutonium reaction, a method for finding some forbidden combinations of solution variables, and properties of plutonium-238 radiation concentration cells.
\end{abstract}




\section{LOGARITHMIC SOLUTION OF THE GENERAL PLUTONIUM EQUILIBRIUM PROBLEM}

Because the element plutonium allows the coexistence in discernable amounts of four seemingly well-defined ions, it offers the possibility of providing colorful experimental tests of many problems in chemistry. The behavior of mixtures of plutonium valence states with changing circumstances of ionic strength may provide an opportunity for testing models of ionic strength, for example. Before plutonium becomes a test for various chemical models, however, it would appear desirable to clarify the probable or expected behavior of equilibrium mixtures of plutonium valence states with important parameters such as acid concentration, average oxidation number, and solution oxidation-reduction potentia1. The term "general plutonium equilibrium problem" has been used to describe methods for interrelating the behavior of plutonium valences with parameters such as those listed above. No completely general solution, i.e., general insofar as inclusion of al1 pertinent parameters (such as ionic strength) and insofar as widespread acceptance has ever been proposed (as of 1974) for the plutonium equilibrium problem, and the problem has not received much attention in recent times. It is the purpose of this section to illustrate a proposed solution to the general plutonium equilibrium problem which does not require a computing machine. The approach developed herein uses the Nernst equation, although there may be simpler approaches to the problem of the equilibrium valence state distribution. Let the symbols, $W, X, Y$, and $Z$ represent ionic (uncomplexed) forms of trivalent, tetravalent, pentavalent, and hexavalent plutonium, respectively. Let the formal potential values of plutonium couples be taken from Reference 1, and let the $\mathrm{W}-\mathrm{Y}$ couple assume the value $1.07605 \mathrm{~V}$ instead of the rounded value of $1.0761 \mathrm{~V}$. Of several Nernst equation combinations which might be selected, let the following be chosen:

$$
E_{W Y}+\frac{N}{2} \log \frac{Y H^{4}}{W}=E_{X Y}+N \log \frac{Y H^{4}}{X}
$$

and let the relative equilibrium value of $Y$ be arbitrarily selected as unity. This has the advantage of reducing the number of unknown variables in Equation 1 from three to two. Equation 1 may be solved for $X$ in terms of $W$ to give, approximately (where $N$, the Nernst constant, is taken as 0.05916):

$$
\mathrm{X} \sim 37.83 \mathrm{H}^{2} \quad \mathrm{~W}^{\frac{1}{2}}
$$


Now choose other Nernst couples such as

$$
E_{W Z}+\frac{N}{3} \log \frac{Z H^{4}}{W}=E_{Z Y}+N \log \frac{Z}{Y}
$$

and let Equation 3 be reduced as follows:

$$
2 \log \mathrm{Z}+\log \mathrm{W}-4 \log \mathrm{H}-5.3955=0
$$

If the solution to the plutonium equilibrium problem is to be general for any average oxidation number ox, then ox must be somewhere included in the solution. This inclusion may take the form of adding a statement of general charge conservation to the equations above,

$$
(3-O X)(W)(A W)+(4-O X)(X)(A X)+(5-O X)(Y)(A Y)+(6-O X)(Z)(A Z)=0
$$

which, under the condition that $Y=1$, may be solved for $Z$ to give

$$
Z=\frac{(O X-3)(W)(A W)+(O X-4)(X)(A X)+(O X-5)(A Y)}{(6-O X)(A Z)}
$$

But Equations 2, 4, and 6 constitute a system of three equations in the three unknowns $W, X$, and $Z$, and may be solved in a variety of ways. Let one way be the substitution of Equations 2 and 6 into Equation 4. Then

$$
\begin{gathered}
2 \log \left[\frac{(\mathrm{OX}-3)(\mathrm{W})(\mathrm{AW})+(\mathrm{OX}-4)(\mathrm{AX})(37.83)\left(\mathrm{H}^{2}\right)\left(\mathrm{W}^{\frac{1}{2}}\right)+(\mathrm{OX}-5)(\mathrm{AY})}{(6-\mathrm{OX})(\mathrm{AZ})}\right]+ \\
\log \mathrm{W}-4 \log \mathrm{H}-5.3955=0
\end{gathered}
$$

where AW, AX, AY, and AZ are the alpha coefficients for trivalent, tetravalent, pentavalent, and hexavalent plutonium respectively, and relate the total concentration of an ion to the uncomplexed concentration of the same ion, e.g., for trivalent plutonium:

$$
\text { total } \mathrm{Pu}(\mathrm{III})=\text { (uncomplexed } \mathrm{Pu}^{3+} \text { ) (AW). }
$$

Equation 7 may be solved with a table of logarithms under various circumstances of $\mathrm{OX}$, acidity $\mathrm{H}$, and alpha coefficients. It is interesting that Equation 7 can be solved with a table of logarithms alone, for the implication of this is that the solution of the general plutonium equilibrium problem did not need to await the advent of computing machines. Probably even simpler solutions than embodied in Equation 7 can be developed. The case of $\mathrm{OX}=4$, a case of particular attention many years ago, is especially simple by Equation 7 . When $\mathrm{OX}=4$ and $\mathrm{H}=1$, for example, Equation 7 becomes (where complexation is neglected and alpha coefficients are taken as unity):

$$
2 \log \left[\frac{W-1}{2}\right]+\log W-5.3955=0
$$


With a table of logarithms, $W$ may be computed to be approximately 100.5 . Then, by Equation 2, X 379.2. But $Y=1$, and therefore Equation 6 predicts $Z \sim 49.75$. A11 of these figures are relative to $Y=1$, so the total amount of plutonium (the sum of all its valence states) is thus, still relative to $\mathrm{Y}=1$, approximately 530.5 . Then $\mathrm{W} \sim 19 \%$ of the total plutonium at equilibrium, and likewise $X \sim 71 \%, Y \sim 0.2 \%$, and $Z \sim 9.4 \%$. If all alpha coefficients had not been unity, then, after computing $W$ from Equation 7, the relative total amount of trivalent plutonium (relative to uncomplexed $\mathrm{PuO}_{z}{ }^{+}=1$ ) could be obtained from the product of $\mathrm{W}$ and $A W$, and a relative measure of the total amount of plutonium could be obtained as the sum of each such product for all oxidation states. The fraction of each oxidation state is, therefore, the value of its respective product divided by this sum. Table 1 illustrates how this approach may be easily substituted into programs in Reference 2 for computing approximate acidity changes. For the REGULA FALSI and bisection methods, it is necessary to change only paragraphs 1,4 , and 12 , as illustrated in Table 1. For operations which require conversion of Napierian and Briggsian logarithms, it is desirable to use the conversion factor 2.3025851 rather than the commonly used forms 2.3 and 2.303. It may be observed that an outstanding unresolved problem in plutonium chemistry is the problem of ascertaining quickly and accurately the final valence state distribution and final acidity given only initial valence state distribution and initial acidity. No method for explicitly solving the problem of final acidity in plutonium solutions has yet been proposed, and such numerical methods as suggested in Reference 2 leave much to be desired. In order to represent equilibrium valence state distributions in dilute acids, it is desirable to be able to correct plutonium equilibrium constants and potentials for ionic strength effects. Since plutonium displays ions of charge +1 to +4 in dilute acids, this is not an easy task. Various methods of making activity coefficient corrections have been suggested, but the range of validity of most ionic strength correction schemes lies below the range of ionic strength ordinarily encountered in plutonium solutions. ${ }^{3}, 4$ However, Costanzo, Biggers, and $\mathrm{Be} 11^{5}$ have provided an equation which they suggest might be useful in the study of plutonium solutions. ${ }^{6}$ Relationships among ionic species, such as in Equation 2, may also be obtained from equilibrium constant expressions. Equation 7 may be taken as an alternative form of the plutonium characteristic equation. 


\section{USE OF COMPUTER PROGRAMS BASED UPON ONE EQUATION \\ AND ONE RECURSION RELATION FOR APPROXIMATING \\ ACIDITY CHANGES IN AQUEOUS PLUTONIUM SOLUTIONS}

There are occasions when it is desirable to be able to ascertain such changes in acid concentrations as may accompany actinide disproportionation reactions. Since the equilibrium valence state distribution in a solution of plutonium depends upon the equilibrium acidity, it is desirable to be able to account for acidity changes which accompany disproportionation reactions so that final equilibrium valence state distributions may be more accurately estimated. Silver ${ }^{2}{ }^{7}$ provided three methods whereby the acidity changes accompanying disproportionation reactions may be estimated: a method based upon the use of Chebyschev polynomials, ${ }^{7}$ a method based upon the classical Regula Falsi method, ${ }^{2}$ and a method based upon the bisection method. ${ }^{2}$ It is important that these three programs are satisfactory for approximation purposes only and that the development of a reliable and versatile method for the accurate assessment of acidity changes in plutonium solutions is still an unresolved problem in plutonium chemistry (however, see Section $V$ of this report). From limited experience with these programs, there appear to be certain generalizations which may assist users of these programs until these programs areireplaced by better methods. For example, two of the programs, the Regula Falsi method and the bisection approach, require the user to suggest the number of iterations (or cycles) of Regula Falsi or bisection. Generally, 6 to 10 iterations are satisfactory in the Regula Falsi approach, and 15 to 20 in the bisection approach. More accurate calculation of the $\mathrm{Pu}(\mathrm{VI}) / \mathrm{Pu}(\mathrm{V})$ ratio, which each method approximates, could be obtained with a larger number of iterations. The small increase in accuracy obtainable by the increased iteration number at this step may not be warranted by the increase in computation time caused by this increased iteration number, however.

A11 three programs require (in addition to an iteration number required by the Regula Falsi and bisection methods) a number of iterations to be performed upon the first estimate of equilibrium acidity and equilibrium valence state distribution. Often, six iterations is sufficient for this purpose in all three programs. It has been found, however, that when the equilibrium acidity is increased by disproportionation reactions, the more of these latter iterations, the better the accuracy, generally speaking, of the final answer. In other words, when the 
equilibrium acidity is increased by disproportionation reactions, convergence to the final answer is often smooth and uncomplicated. When the final equilibrium acidity is decreased by disproportionation reactions, however, convergence may not be possible, and the answer which best appoximates the true answer may be obtained with as few iterations on the first estimate of the equilibrium valence state distribution and equilibrium acidity as possible. (A way to check this is to solve the problem more than once starting with a few and increasing to several iterations upon the first estimate of equilibrium conditions.) Precisely why the decrease or increase in equilibrium acidity should sometimes be accompanied by failure to converge to the correct answer is not presently known. Divergence upon changing the equilibrium acidity does not always occur, however, and there may be a rough rule for predicting trouble.

RULE: For any given initial valence state distribution, reproportion the ions in such a manner as to cause maximum decrease in solution acidity. It does not matter if this supposed valence state distribution is not the equilibrium valence state distribution. If the change in acid concentration induced by this supposed valence state distribution causes the initial acidity to drop to zero or below, failure to converge may be anticipated.

Example 1. A plutonium solution is prepared by dissolving 0.1 mole of $\mathrm{Cs}_{2} \mathrm{PuCl}_{6}$ in a liter of $0.6 \mathrm{M}$ perchloric acid. In this case, convergence to a reasonably accurate description of the final equilibrium conditions should be uncomplicated. The state of initial plutonium is $100 \%$ tetravalent; the disproportionation of tetravalent plutonium increases the equilibrium acidity, and the rule predicts no convergence problems.

Example 2. A plutonium solution is prepared by dissolving two-tenths mole of pure pentavalent plutonium in $800 \mathrm{ml}$ of $0.3 \mathrm{M}$ perchloric acid. Pentavalent plutonium may be reproportioned, for purposes of rule testing, into one-tenth mole tetravalent plutonium and one-tenth mole hexavalent plutonium:

$$
2 \mathrm{Pu}(\mathrm{V})+4 \mathrm{H}^{+}=\mathrm{Pu}(\mathrm{IV})+\mathrm{Pu}(\mathrm{VI})+2 \mathrm{HOH} \text {. }
$$

This requires the consumption of four-tenths mole hydrogen ion. But the solution contained only 0.24 mole hydrogen ion to begin with. Hence the final equilibrium amount of acid is predicted to be $0.24-0.40=-0.16$ mole. But this is below zero, so the rule predicts unsatisfactory convergence of the programs, and an inaccurate answer.

Example 3. A plutonium solution is prepared by dissolving in a liter of $1.10 \mathrm{M}$ perchloric acid, 0.25 mole Pu(III), 0.25 mole Pu(IV), 0.25 mole $\mathrm{Pu}(\mathrm{V})$, and 0.25 mole $\mathrm{Pu}(\mathrm{VI})$. The pentavalent plutonium may be proportioned into 0.125 mole $\mathrm{Pu}(\mathrm{IV})$ and 0.125 mole $\mathrm{Pu}(\mathrm{VI})$, consuming $0.5 \mathrm{~mole}$ of acid in the process. This leaves 0.25 mole $\mathrm{Pu}$ (III), 0.375 mole $\mathrm{Pu}(\mathrm{IV})$, no $\mathrm{Pu}(\mathrm{V})$, and 0.375 mole $\mathrm{Pu}(\mathrm{VI})$. But hexavalent and trivalent plutonium may reproportion: 


$$
\mathrm{Pu}(V I)+2 \mathrm{Pu}(\mathrm{III})+4 \mathrm{H}=3 \mathrm{Pu}(\mathrm{IV})+2 \mathrm{HOH} .
$$

This reproportionation leaves no $\mathrm{Pu}(\mathrm{III})$ and $0.25 \mathrm{~mole}$ of $\mathrm{Pu}(\mathrm{VI})$ and consumes 0.5 mole of acid in the process. Hence, the equilibrium acidity is predicted to be $1.10 \mathrm{M}-1.00 \mathrm{M}=0.10 \mathrm{M}$. While $0.10 \mathrm{M}$ is above zero, it is nevertheless close to zero for purposes of the rule. Hence, this is a borderline case, and the rule, which is only a rough guide, is not much help. The only way to find out about the convergence is to test the problem. In applying the rule, it is important that the absolute quantity of plutonium as well as its initial distribution must be considered. Fortuitous $1 y$, cases of decreasing acidity which lead to divergent behavior of the programs are often the circumstances in which tetravalent plutonium might polymerize, and the programs would thus not be applicable.

It seems desirable to note that of the three programs, the program in Reference 7 (and as modified below) utilizing Chebyschev polynomials is the fastest. The bisection method is the slowest. It also seems desirable to note that the three programs approach the first approximation of the equilibrium in entirely different manners. The Chebyschev program approaches the first approximation to final equilibrium conditions by a parabolic path: $G^{2} / 400$, where $G$ is incremented by unity until it reaches its maximum value of 20 . When $G=20$, the first approximation of equilibrium conditions has been obtained. Successive approximations on the equilibrium conditions keep $G=20$. (See Figure 1, line A) The Regula Falsi method uses a linear approach to the first approximation of final equilibrium conditions: $\mathrm{L} / 20$, where $\mathrm{L}$ is incremented by unity until $\mathrm{L}=20$, and then held at $\mathrm{L}=20$ for all successive equilibrium approximations. (See Figure 1, line B) The bisection method approaches its first approximation of final equilibrium conditions in an inverse parabolic manner: $0 / 20$, where 0 (the alphabetic letter) is the square root of $(\mathrm{L}+20)$ and $\mathrm{L}$ is incremented by 20 until 0 reaches its highest value of $0=20$. (See Figure 1 , line $C$ )

There is a certain question of favoritism in all three programs; i.e., which should come last, the approximation of the equilibrium valence state distribution (which requires the last approximation of the equilibrium acidity) or the approximation of the equilibrium acidity (which requires the last equilibrium valence state approximation). Since an estimate of the equilibrium valence state distribution is necessary to compute the next estimate of equilibrium acidity, and since an estimate of the equilibrium acidity is necessary to compute the next equilibrium valence state distribution, it is evident that both cannot be last. Hence, there will ordinarily be some discrepancy between the calculated equilibrium acidity and the calculated valence state distribution. The extent of the discrepancy, if any, is easily estimated by taking the computed equilibrium acidity and solving the general plutonium equilibrium problem in the $\mathrm{N}, \mathrm{H}$ form using this acidity as " $\mathrm{H}$ " and the average oxidation number associated with the initial valence state distribution as " $N$ ". Likewise the general plutonium equilibrium problem can be solved in terms of $\mathrm{N}$ and $\mathrm{F}$ (the computer calculated amount of hexavalent 
plutonium) and then comparing the acidity values from the $\mathrm{N}, \mathrm{F}$ program and the approximate acidity changes program.

There are several internal checks which can be made on the precision of the answer obtained by the programs for computing acidity changes. Below are several suggested tests. The computer calculated amounts of tetravalent actinide is the sum of $\mathrm{A}^{4+}+\mathrm{AOH}^{3+}$, the amount of $\mathrm{A}^{4+}$ can be obtained by subtracting $\mathrm{A}(4) \mathrm{OH}$ (which is $\mathrm{AOH}^{3+}$ ) from $\mathrm{A}(4)$ (which $\left.\mathrm{A}^{4+}+\mathrm{AOH}^{3+}\right)$ or by dividing $\mathrm{A}(4)$ by its alpha coefficient $\left(1+\mathrm{KH} / \mathrm{H}^{+}\right)$ where the only complexation of $A^{4+}$ is its first hydrolysis reaction. Also let $\mathrm{W}, \mathrm{X}, \mathrm{Y}$, and $\mathrm{Z}$ represent ionic (uncomplexed) $\mathrm{A}^{3+}, \mathrm{A}^{4+}, \mathrm{AO}_{2}^{+}$, $\mathrm{AO}_{2}^{2+}$. For any valence state $\mathrm{V}$, total V, ionic $\mathrm{V}$, and the alpha coefficient for $V$ are related as follows:

$$
V(\text { tota } 1)=V(\text { ionic }) \times \text { Alpha Coefficient for } V \text {. }
$$

Test 1. Does the quotient WZ/XY of computed valence states equal the selected value of $\mathrm{K}_{2}$ exactly? If $\mathrm{K}_{2}$ were selected as 13.2 , a quotient of 13.15 would reflect some internal discrepancy in the computed equilibrium valence state distribution. Unfortunately, this test gives no hint of the significance of the discrepancy or of its magnitude or origin.

Test 2. Does the sum $A(3)+A(4)+A(5)+A(6)$ equal 1.0? ("A" represents the fraction of total actinide of oxidation state given in parentheses.)

Test 3. Is the average oxidation number of the final valence state distribution equal to the average oxidation number of the initial valence state distribution? Because of truncation in printed valence state assignments, it may not be easy to estimate the significance of any discrepancy between the initial and final $\mathrm{N}$ values. An initial $\mathrm{N}$ of 4.00 , for example, and a final $\mathrm{N}$ of 3.98 would certainly indicate a problem, however. Also, is the charge conservation statement for the initial valence state distribution maintained by the computed equilibrium valence state distribution? ( $N$ is average oxidation number)

Test 4. Is the quotient $W Y H^{4} / \mathrm{X}^{2}$ of computed values equal to the selected value of $\mathrm{K}_{1}$ exactly? A discrepancy between the assigned value of $\mathrm{K}_{1}$ and the computed value indicates a discrepancy between the computed equilibrium acidity and the associated valence state distribution. Usua11y there is a discrepancy at this point, but if the discrepancy does not exceed about one part per thousand, the acidity value and va1ence state distribution have probably been satisfactorily estimated, provided other tests are satisfied.

Test 5. Tests $1-4$ are all related to the general plutonium equilibrium problem, but this test is independent of that approach. Examine the initial valence state distribution and the computed final equilibrium valence state distribution. Calculate the change in the number of moles of hexavalent plutonium, pentavalent plutonium, and hydrolyzed tetravalent 
plutonium. If any one of these has increased, then the equilibrium acidity has been thereby increased, and if any one of them has decreased, then the equilibrium acidity has been thereby also decreased. Multiply the change in the number of moles of hexavalent plutonium by four, and add or subtract this number to or from the initial acidity according to whether hexavalent plutonium increased or decreased. Do this likewise with pentavalent plutonium. Alternatively, add together the fractions of $\mathrm{Pu}(\mathrm{VI})$ and $\mathrm{Pu}(\mathrm{V})$. If this sum is greater than the initial sum, then the acidity has increased by four times the difference, and if the final sum is less than the initial sum, then the acidity has likewise decreased, making due allowance for the total molar amount of plutonium ions which the fractions of $\mathrm{Pu}(\mathrm{VI})$ and $\mathrm{Pu}(\mathrm{V})$ represent. Also do this operation with $\mathrm{A}(4) \mathrm{OH}$, except that the multiplier is unity instead of four. The initial acidity adjusted in this manner should equal the computed equilibrium acidity. Ordinarily, there will be some discrepancy revealed by this test. The question is, is this discrepancy tolerable to the user?

Test 6. Take the computed valence state distribution with its associated acidity and reenter them into the program as a new problem. If the initial approximation were a good approximation, there will be very little difference between the first and second approximations. In cases where divergence (or grossly incomplete convergence) occurs, it is usua1ly desirable to use the last computed acidity (H2), rather than the printed acidity value, which is a geometric average of the last two computed acidity values. The value of $\mathrm{H} 2$ may be easily called from the programs .

There is usua11y a significant change in solution ionic strength as disproportionation reactions occur. It follows that equilibrium constants appropriate to the final conditions of solution acidity and ionic strength should be selected, but because of the dependence of the numerical values of $\mathrm{K}_{1}$ and $\mathrm{K}_{2}$ upon ionic strength is so poorly understood, it would appear that programs which only approximate the effects of disproportionation reactions (such as the ones discussed herein) must suffice until an accurate dependence of $\mathrm{K}_{1}$ and $\mathrm{K}_{2}$ upon ionic strength is elucidated. Nevertheless, an exact solution to the acidity changes problem should be developed. It is sometimes interesting to insert a statement "Type $\mathrm{H}^{\prime \prime}$ into the programs so that the approach to equilibrium acidity can be observed. There will be occasional times when the acidity decrease from initial to final conditions is so severe that the bisection and Regula Falsi programs will be insufficiently flexible to accomodate it. The flexibility of the programs for this circumstance may be considerably improved by decreasing the constant in step 12.32 from 0.0625 to a lower number such as 0.0100 or 0.0050 or even lower. This change would not be an advantage in any other circumstance, however, and would usually be a disadvantage since it considerably lengthens the running time of the programs (which is nearly 5 min). A circumstance requiring this change would arise only rarely, and only with relatively large molar concentrations of plutonium. When large decreases in solution equilibrium acidity can reasonably be expected, there may be occasional advantage in discounting the acidity decrease 
prior to attempting numerical solution. For example, suppose the final conditions of equilibrium acidity were desired for the circumstance in which two-tenths mole of pentavalent plutonium were introduced into a liter of one molar acid. This may be entered into one of the programs as $0.2 \mathrm{M}$ plutonium, the distribution of which is $1.00 \mathrm{Pu}(\mathrm{V})$. Alternatively, it may be entered into a program by first using Equation 9 so that the initial conditions are $0.2 \mathrm{M}$ plutonium, the distribution of which is $0.5 \mathrm{Pu}(\mathrm{IV})$ and $0.5 \mathrm{Pu}(V I)$ in $0.6 \mathrm{M}$ acid.

There is in existence a much older program ${ }^{8}$ for performing estimations of final plutonium solution equilibrium conditions. This older program uses FORTRAN language and is designed for an IBM machine. While this program is also useful, it suffers at least three shortcomings. The old program solves two equations simultaneously in the course of its operation. This results both in loss of accuracy and increased running time. This shortcoming may be overcome by substituting for the two simultaneous equations a single polynomia $1^{\circ}$ for plutonium in aqueous solution, solving this polynomial quickly for $\mathrm{M}$, the $\mathrm{Pu}(\mathrm{VI}) / \mathrm{Pu}(\mathrm{V})$ ratio, and proceeding from there. The older program uses a fixed initial guess for the proportion of $\mathrm{Pu}(\mathrm{VI})$ of $10^{-12}$. This is often a poor place to begin. A more versatile approach is outlined elsewhere. ${ }^{2}$ The old program uses only the Newton-Raphson approximation method. For a program such as given in Reference 8, this is often a poor selection of a single numerical method. Better single methods are available.

In cases of program failure in the Regula Falsi or bisection approaches, the searched interval (the upper limit of which is determined by statement 3.02 of these programs) might be changed to good advantage. Not only do the three programs approach the first estimate of equilibrium conditions by completely different paths, so also does the method of final answer extraction differ. This usually leads to small differences in computed answers, the most accurate of which can be assayed by the six tests above. Two test problems were run on each of the three programs under the following conditions: number of iterations in acidity convergence step, 10; number of Regula Falsi iterations, 10; number of bisection iterations, 22. Problem one was the introduction of one mole of pure tetravalent plutonium into a liter of $0.5 \mathrm{M}$ acid. In this problem, each program converged to a final acidity of $0.925012 \mathrm{M}$ exact $1 \mathrm{y}$. Problem two was the introduction of one mole of plutonium $[0.25$ part each $\mathrm{Pu}(\mathrm{III}), \mathrm{Pu}(\mathrm{IV}), \mathrm{Pu}(\mathrm{V})$, and $\mathrm{Pu}(\mathrm{VI})]$ into a liter of one molar acid. The bisection program gave as the final acidity $0.459822 \mathrm{M}$, the Regula Falsi program gave $0.459745 \mathrm{M}$, and the Chebyschev program gave $0.459640 \mathrm{M}$. In the second problem, convergence was smooth toward the final answer, but incomplete with ten iterations in the acidity convergence step. In such cases, insertion of a "Type $\mathrm{H}^{\text {" }}$ statement into the programs is very helpful for viewing and judging the degree of completeness of convergence. $\mathrm{K}_{1}, \mathrm{~K}_{2}$, and $\mathrm{KH}$ were taken as $6.97 \mathrm{E}-04,13.2$, and $3 \mathrm{E}-02$, respectively, and all alpha coefficients were taken as unity. The Regula Falsi and bisection programs are derived from similar programs used to generate tables of actinide valence state distributions. These latter programs contain many "DO" commands which good programming 
technique might suggest change to "GOTO" commands in order that "DO" statements might thereby not be too deeply nested. When applying the rule above to rearrange valence state distributions, mass conservation, Test 2 , and charge conservation, Test 3 , must be obeyed for al1 rearranged valence distributions. The older, FORTRAN program used terms called "alpha factors". These "alpha factors" are synonymous with "alpha coefficients", the ratio of the total amount of an oxidation state (ionic form plus all complexes) to the ionic form of the same oxidation state. Table 2 provides a modified version of the Chebyschev approach. It seems likely that improved programming techniques could render such programs as discussed in this section more than approximation methods. The "equation" used in these three programs is the statement of the general plutonium equilibrium problem in the $(\mathrm{N}, \mathrm{H})$ form (Equation 34 herein) and the "recursion relation" is given as Equation 49 in Reference 8 . 


\section{PLUTONIUM-238 RADIATION CONCENTRATION CELLS}

The purpose of this section is to suggest that radioisotopes which appear as a by-product of commerical nuclear processes may find application in low power batteries. It is well known that the dissipation of energy from radioactive substances often results in chemical changes in surrounding materials. The generation of nitrogen oxides, chlorine, or hydrogen peroxide in solutions of radioisotopes is an example of chemically reactive species which may be generated by radioactivity in aqueous solutions. ${ }^{10}$ Such electrochemically active species may be used for electric power generation provided that some driving force, such as a concentration gradient, can be instituted between the anode and cathode compartments of the proposed battery.

Two glass tubes, about $\frac{1}{2}$ in. in diameter and about $1 \frac{1}{2}$ in. long, were each sealed at one end. A platinum wire extended through the seal from the outside to the inside of each tube. One tube was fitted with a female ground glass joint and the other with a male ground glass joint in order that the tubes could be joined together. Into one tube was placed a smaller amount of plasma-fired plutonium-238 dioxide microspheres, and into the other tube was placed a larger amount of plutonium238 dioxide microspheres. ${ }^{11}$ Plasma-fired ${ }^{238} \mathrm{PuO}_{2}$ microspheres are characterized by their inertness and insolubility. Dilute hydrobromic acid was selected as the working electrolyte because bromine, one product of the irradiation of dilute solutions of hydrobromic acid, is soluble in water. Moreover, the bromine-bromide oxidation-reduction couple is relatively reversible, thus allowing a rapid poising of the electrodes. The microspheres were thoroughly washed with $2 \mathrm{M} \mathrm{HBr}$ and then each half of the battery (containing greater and lesser quantities of microspheres, respectively) was allowed to stand overnight in $2 \mathrm{M} \mathrm{HBr}$ so that radiation induced oxidation-reduction products could accumulate. The two halves of the battery were then joined together, the battery placed on a horizontal surface, and the voltage observed for a few hours. A similar battery was prepared with $0.5 \mathrm{M} \mathrm{HBr}$. Results are shown in Table 3 . Analysis of the $0.5 \mathrm{M} \mathrm{HBr}$ solution showed it to contain less than $7.5 \times 10^{-4} \mathrm{mg} / \mathrm{ml}$ plutionium, a level of plutonium which is the result of background contamination during alpha count analysis. The microspheres contained about $80 \%$ plutonium-238 and $20 \%$ plutonium-239.

The potential of each electrode (vs. N.H.E.) is given in millivolts approximately by 


$$
E=E^{0}+30 \log \frac{\left[\mathrm{Br}_{2}\right]}{\left[\mathrm{Br}^{-}\right]^{2}}
$$

where $\left[\mathrm{Br}_{2}\right]$ represents the concentration of the radiation induced oxidizing agent (bromine) and $\left[\mathrm{Br}^{-}\right]$represents the concentration of the bromide ion, the reduced form of the redox couple. In this case $E^{0}$ represents the standard half cell potential of the bromine-bromide couple. For each electrode, $\mathrm{E}^{0}$ has the same value, and the concentration of the bromide ion is approximately equal at each electrode since only one homogeneous electrolyte was used. The bromine concentration differs at each electrode, however, because of the differing levels of radioactivity at each end of the cell. Hence, cell 非 2 generates more voltage than cell 非, because the radioactivity levels between the two ends of cell 非 differ by a factor of 4, whereas these levels in cell 非 2 differ by a factor of 20 .

Since the amount of bromine generated by the radioactive microspheres is proportional (as a first approximation) to the quantity of microspheres in the cell, the Nernst Equation may be used to approximate the voltage of the cells.

$$
\text { Voltage } \sim 30 \log \frac{100}{5} \sim 39 \mathrm{mV}
$$

The predicted voltage of about $39 \mathrm{mV}$ agrees with the observed voltage of about $35 \mathrm{mV}$ for cell 非. For cell 非 1 however, the predicted voltage of about $18 \mathrm{mV}$ is larger than the observed voltage of about $8 \mathrm{mV}$. This discrepancy may arise in several ways. The cell was operated in a horizontal position, and some of the microspheres may thus have rolled away from the electrode toward the center of the cell. Much of the bromine generated by such displaced microspheres would be at such a distance from either electrode as to be lost for purposes of power generation. Moreover, alpha particles emitted from a microsphere within a pile of microspheres may penetrate neighboring microspheres and there dissipate their energy as heat instead of dissipating their energy in the electrolyte solution.

In batteries such as the concentration cells discussed herein, the electrolyte acts as its own salt bridge; bromine may reach the electrode by diffusion or turbulence caused by gas bubbles. The radioactive ${ }^{2}{ }^{8} \mathrm{PuO}_{2}$ particles may be suspended near the electrodes by, for example, wire mesh baskets. Since the radioactive material is insoluble and localized, accidental breakage of the battery will not result in widespread radioactive contamination. As the voltage capable of being generated is not related to the total quantity of radioisotope in a simple, linear way as is the case in thermal batteries, very small quantities of radioisotope might be practical and no cooling mechanisms would be required to dissipate unwanted heat. In reversible systems, it is necessary for radioactive material to be present at one electrode only. 
Electroactive species may accumulate during periods of inactivity for use at a later time, providing a limited form of energy storage. The recombination of hydrogen and bromine does not readily occur at room temperature except on certain catalytic surfaces. Since oxidation and reduction of chemical species within a closed system must occur to equal extent, hydrogen gas in the form of bubbles accompanies the radiative generation of bromine. Unless the hydrogen and bromine can recombine, the electrolyte hydrogen bromide could be depleted. Hence the electrodes may also serve as a catalytic surface to regenerate the hydrogen bromide so that excessive amounts of hydrogen gas do not accumulate. For this purpose, catalytic surfaces may also be present elsewhere in the battery. Since electrode geometry may be expected to affect the battery efficiency, it might be desirable to replace the anode and cathode wires with other electrode forms, e.g., plates. Plutonium-238 generates heat at a rate of about $0.57 \mathrm{~W} / \mathrm{g}$. Fence, cell 非 2 generates about $0.048 \mathrm{~W}$. Assuming $4 \%$ efficiency of conversion to electrical energy, this represents a potential electrical power output of about $2 \mathrm{~mW}$. Cell 非, with thin wire electrodes, generates only about $0.4 \mu \mathrm{W}$ of power. Diffusion, current flow, and the generation of gas bubbles may act to upset the concentration gradients in the battery, and this may produce variations in the steady state voltage. It may be observed that, if the batteries discussed herein were operated in a vertical position, all of the microspheres and bromine would accumulate at the bottom electrode, whereas any generated hydrogen gas bubbles would accumulate at the top electrode. In this manner, it might be possible to operate the battery as a hydrogenbromine battery with the development of much higher steady state voltages.

The efficiency of this type of chemical energy conversion device is not very great. Many of the alpha or other particles which are capable of generating electroactive species will dissipate their energy entirely within the microsphere of radioisotope, or, in the case of gamma radiation, escape the system altogether. In either case, much of the radioactive decay energy will be lost to the battery. Even neglecting energy losses such as this, however, the anticipated efficiency is low, may depend upon the working electrolyte, and may be estimated in more than one manner as illustrated below.

There are about $6.28\left(10^{18}\right)$ electrons per coulomb. Suppose that the energy of an alpha particle is $5.5\left(10^{6}\right) \mathrm{eV}$, and that the energy required to generate an ion pair in the electrolyte is $35 \mathrm{eV} .^{10}$ Hence, at most there may be generated $1.6\left(10^{5}\right)$ ion pairs per alpha. Since there are $3.7\left(10^{10}\right)$ alphas per second per curie, it follows that there can be no more than $6\left(10^{15}\right)$ ion pairs per second per curie of radioisotope assuming that all the alpha particles deposit all of their energy in the solution, an unrealistically generous assumption. Now, the current capability of this system, if each ion pair donates one electron to or receives one electron from the anode and cathode, respectively, is

$$
\frac{(6)\left(10^{15}\right) \text { electrons }}{\text { second-curie }} \div \frac{(6.28)\left(10^{18}\right) \text { electrons }}{\text { second-ampere }} \sim 10^{-3} \frac{\text { ampere }}{\text { curie }}
$$

assuming no ion pair recombination prior to electrode reaction. If the 
electron exchange occurred at $0.5 \mathrm{~V}$, a very liberal estimate, then the maximum power output is $0.5 \mathrm{~mW} / \mathrm{Ci}$. It is approximately true that one curie of plutonium-238 can be converted by thermal means to one milliwatt of electrical energy. It follows that the type of chemical energy conversion device envisioned here is much less than $50 \%$ as efficient as a thermal conversion device, and that the battery discussed here would be of interest in circumstances where only a tiny amount of radioisotope were tolerable.

It may also be supposed, since alpha particles emitted by plutonium-238 atoms near the center of a microsphere may have insufficient energy to escape the microsphere, that the energy of these alpha particles is not available for purposes of power generation and therefore should not be included in efficiency calculation. The fraction of total alpha particles escaping a sphere as a function of the radius of the sphere and the range of the alpha particle within the sphere has been given in Reference 12 .

Consider a microsphere of nominal diameter about $200 \mu \mathrm{m}$. The fraction of total alpha particles which escape the sphere is about 0.085 , and the number of alpha particles escaping the microsphere is about (1.17)( $\left.10^{8}\right)$ particles per minute. ${ }^{12}$ The alpha energy spectrum of typical microspheres is also given in Reference 12. The area under the theoretical alpha energy curve may be approximated by a right triangle. An approximate measure of the particle input to the solution is the area of this right triangle. Since the base of the triangle has a value of $5.5 \mathrm{MeV}$, it is necessary only to compute the height of the triangle at $5.5 \mathrm{MeV}$ in order to obtain a measure of the area of the triangle.

Since the imagined straight line which forms the hypotenuse of the right triangle in Figure 3 of Reference 12 passes through the origin, the channel number (i.e., energy range) and the number of alpha particles in the given channel are related by a multiplicative constant only. That is, if there are " $S$ " alpha particles per minute in channel number one, then there will be $240 \mathrm{~S}$ particles in channel number 240 . Then the total number of alpha particles escaping the microsphere per minute is approximately

(S) $\sum_{1}^{240}(C)$ where " $C$ " is the channel number. Hence

(S) $\sum_{1}^{240}(C)=\frac{(240)(241)(S)}{2}=(1.17)\left(10^{8}\right)$ or

$$
\mathrm{S} \sim(4.05)\left(10^{3}\right) \text { particles/minute-channel }
$$

The total number of particles in channel 240 is thus about (9.7) (105). A measure of the energy delivered to the solution at any channel is the product of the number of particles in the channel and the energy of the 
particles in the channel. The sum of all such products for all channels is a measure of the total energy delivered to the solution by the alpha particles:

$\sum_{1}^{240}(\mathrm{~S})(\mathrm{C}) \cdot \frac{(\mathrm{C})(5.5)}{240} \sim(4.3)\left(10^{8}\right) \mathrm{MeV} / \mathrm{min}$

or about $1.15 \mu \mathrm{W}$ per microsphere. Since each microsphere weights about $50 \mu \mathrm{g}$, cell 非 2 contained about 2100 microspheres. This represents a potential power of about $2400 \mu \mathrm{W}$. Hence, the efficiency of cell 非 based upon this estimate of available power is only about $0.01 \%$; based upon total contained power of $0.048 \mathrm{~W}$, only about $0.0008 \%$; and based upon $4 \%$ thermoelectric conversion of the total contained power, only about $0.02 \%$. Further discussions of systems which may be applicable to the problem of power generation by alpha particle emission can be found in References 13 and 14. 


\section{THE IRON-PLUTONIUM REACTION}

One of the interesting applications of the polynomial approach to the representation of chemical elements is the extension of this approach to the study of chemical reactions. Cleveland ${ }^{15}$ has remarked the interest and attention which the kinetics of the reaction of iron with the various plutonium ions has attracted. This reaction provides an illustration of the extension of the polynomial approach into the area of chemica1 reactions.

The portions of the various plutonium ions in aqueous solution relative to $\left[\mathrm{PuO}_{2}^{+}\right] \equiv 1$ have been given ${ }^{7}$ by Equations 17-20:

$$
\begin{aligned}
& \mathrm{Pu}(\mathrm{III})=\frac{\left(\mathrm{K}_{\mathrm{L}}^{2}\right)(\mathrm{AW})\left(\mathrm{H}^{4}\right)}{\left(\mathrm{K}_{1}\right)\left(\mathrm{M}^{2}\right)} \\
& \mathrm{Pu}(\mathrm{IV})=\frac{(\mathrm{AX})\left(\mathrm{K}_{2}\right)\left(\mathrm{H}^{4}\right)}{\left(\mathrm{K}_{1}\right)(\mathrm{M})} \\
& \mathrm{Pu}(\mathrm{V})=\mathrm{AY} \\
& \mathrm{Pu}(\mathrm{VI})=(\mathrm{AZ})(\mathrm{M})
\end{aligned}
$$

where $M$ is the ratio of ionic hexavalent plutonium to ionic pentavalent plutonium. The reaction of iron with plutonium may be expressed in terms of a mass conservation statement for the iron and plutonium taken together or in terms of a charge conservation statement for these two elements taken together. Only the latter approach is discussed here. For iron and plutonium taken together, the charge conservation statement may be expressed as in Equation 21:

$$
\begin{aligned}
& (3-\mathrm{N})[\mathrm{Pu}(\mathrm{III})]+(4-\mathrm{N})[\mathrm{Pu}(\mathrm{IV})]+(5-\mathrm{N})[\mathrm{Pu}(\mathrm{V})]+(6-\mathrm{N})[\mathrm{Pu}(\mathrm{VI})] \\
& +(2-\mathrm{N})[\mathrm{Fe}(\mathrm{II})]+(3-\mathrm{N})[\mathrm{Fe}(\mathrm{III})]=0
\end{aligned}
$$

where symbols suffixed by Roman numerals represent total concentrations or fractions.

Let $\mathrm{AW}, \mathrm{AX}, \mathrm{AY}, \mathrm{AZ}, \mathrm{A} 2$, and $\mathrm{A} 3$ be the alpha coefficients for trivalent, tetravalent, pentavalent, and hexavalent plutonium and divalent and trivalent iron, respectively. In order to characterize the nature of the iron-plutonium equilibrium in a solution of given, fixed acidity 
and alpha coefficients, the initial state of the plutonium is desirable, the initial state of the iron is desirable, the amount of iron relative to the amount of plutonium is desirable, and some connection between iron and plutonium must be established. The initial state of the plutonium may be characterized by stating its average oxidation number, NP, and the initial state of the iron may be characterized by stating its average oxidation number, NF. The average oxidation number of the elements in the reaction, i.e., the average oxidation number of a11 substances of interest, may be obtained by specifying the relative amounts of iron and plutonium:

$$
\text { (total iron) }=\mathrm{R}(\text { total plutonium) }
$$

where " $R$ " is the ratio of iron to plutonium. Then the average oxidation number of both the substances of interest taken together is

$$
\frac{[\mathrm{NP}+\mathrm{R}(\mathrm{NF})]}{(1+\mathrm{R})}=\mathrm{N} \text {. }
$$

Equation 22 may be rewritten to express the relationship of iron and plutonium as in Equation 24

$$
\mathrm{A} 2\left[\mathrm{Fe}^{2+}\right]+\mathrm{A} 3\left[\mathrm{Fe}^{3+}\right]=\mathrm{R}[\mathrm{TA}]
$$

where "TA" represents a measure of the total actinide in solution, i.e., the sum of the right hand members of Equations 17-20. Iron and plutonium may be chemically connected by any of several reactions. Choose Equation 25

$$
\mathrm{PuO}_{2}^{2+}+\mathrm{Fe}^{2+}=\mathrm{Fe}^{3+}+\mathrm{PuO}_{2}^{+}
$$

for which the equilibrium constant, $K R$, may be taken as about 300 . Then

$$
\mathrm{KR}=\frac{\left[\mathrm{Fe}^{3+}\right]}{\left[\mathrm{Fe}^{2+}\right] \mathrm{M}}
$$

and

$$
\text { (A2) }\left(\mathrm{Fe}^{2+}\right)+(\mathrm{A} 3)(\mathrm{KR})(\mathrm{M})\left(\mathrm{Fe}^{2+}\right)=(\mathrm{R})(\mathrm{TA}) \text {. }
$$

Hence

$$
\mathrm{Fe}^{2+}=\frac{(\mathrm{R})(\mathrm{TA})}{\mathrm{A} 2+(\mathrm{A} 3)(\mathrm{KR})(\mathrm{M})}
$$

and

$$
\mathrm{Fe}^{3+}=\frac{(\mathrm{KR})(\mathrm{M})(\mathrm{R})(\mathrm{TA})}{\mathrm{A} 2+(\mathrm{A} 3)(\mathrm{KR})(\mathrm{M})}
$$


It follows that the general charge conservation statement for the ironplutonium reaction is

$$
\begin{aligned}
& \frac{(\mathrm{AW})\left(\mathrm{K}_{2}^{2}\right)(3-\mathrm{N})\left(\mathrm{H}^{4}\right)}{\left(\mathrm{K}_{1}\right)\left(\mathrm{M}^{2}\right)}+\frac{(\mathrm{AX})(4-\mathrm{N})\left(\mathrm{K}_{2}\right)\left(\mathrm{H}^{4}\right)}{\left(\mathrm{K}_{1} \mathrm{M}\right)}+(5-\mathrm{N})(\mathrm{AY})+(6-\mathrm{N})(\mathrm{AZ})(\mathrm{M}) \\
& +\frac{(\mathrm{A} 2)(2-\mathrm{N})(\mathrm{R})(\mathrm{TA})}{\mathrm{A} 2+(\mathrm{A} 3)(\mathrm{KR})(\mathrm{M})}+\frac{(\mathrm{A} 3)(3-\mathrm{N})(\mathrm{KR})(\mathrm{M})(\mathrm{R})(\mathrm{TA})}{\mathrm{A} 2+(\mathrm{A} 3)(\mathrm{KR})(\mathrm{M})}=0
\end{aligned}
$$

After clearing " $M$ " from denominators, Equation 30 may be solved by a variety of machine techniques. Table 4 provides a FOCAL language statement of the iron-plutonium equilibrium. Doubtless simpler, more accurate approaches are also available. When one part of iron with $\mathrm{NF}=2.0$ is added to one part of plutonium with $\mathrm{NP}=5$, then $\mathrm{N}=3.5$ and the $\mathrm{Pu}$ equilibrium valence state distribution is nearly that of a plutonium solution with NP $=4.0$. The adverb "nearly" may be added since the magnitude of $\mathrm{KR}$ is insufficient to make the reaction in Equation 25 essentially quantitative.

It may be observed that charge conservation statements such as Equation 30 may be used to estimate regions of tolerable and forbidden variable combinations. Although there is no general agreement on the values of $\mathrm{K}_{1}$ and $\mathrm{K}_{2}$ for plutonium (which makes the exact boundary between tolerable and forbidden variable combination regions difficult to define), a reasonable approximation of the plutonium polynomial (neglecting complexation and hydrolysis) can probably be stated by Equation 31 a or $31 b$

$$
\text { (25) } \begin{aligned}
\left(10^{4}\right)\left(\mathrm{H}^{4}\right)(3-\mathrm{N}) & +(1.9)\left(10^{4}\right)\left(\mathrm{H}^{4}\right)(\mathrm{M})(4-\mathrm{N})+(5-\mathrm{N}) \mathrm{M}^{2} \\
& +(6-\mathrm{N}) \mathrm{M}^{3}=0 .
\end{aligned}
$$

In Equation 31a, all alpha coefficients have been taken as unity. Equation 31 a may be solved for the acidity term $\mathrm{H}^{4}$ :

$$
\mathrm{H}^{4}=\frac{(\mathrm{N}-5) \mathrm{M}^{2}+(\mathrm{N}-6) \mathrm{M}^{3}}{(25)\left(10^{4}\right)(3-\mathrm{N})+(1.9)\left(10^{4}\right) \mathrm{M}(4-\mathrm{N})}
$$

Let $\mathrm{N}=5.5$, then Equation $3 \mathrm{lb}$ becomes

$$
\mathrm{H}^{4}=\frac{0.5 \mathrm{M}^{\mathrm{P}}-0.5 \mathrm{M}^{3}}{(-62.5)\left(10^{4}\right)+(-2.85)\left(10^{4}\right) \mathrm{M}}=\frac{0.5 \mathrm{M}^{3}-0.5 \mathrm{M}^{\mathrm{P}}}{(62.5)\left(10^{4}\right)+(2.85)\left(10^{4}\right) \mathrm{M}}
$$

When $\mathrm{N}=5.5$, Equation $31 \mathrm{a}$ and $\mathrm{b}$ cannot be satisfied by any $\mathrm{M}$ less than unity. When $M<1$, Equation 32 shows that the acidity, $H$, is the fourth root of a negative number. But this is impossible, so $M$ cannot be less than unity for $N=5.5$, and for $N=5.5$, any $M<1$ lies in a forbidden $\mathrm{N}$, $\mathrm{M}$ region. When $\mathrm{M}<1$, then the potential of the solution is less than about $0.916 \mathrm{~V}$, so that a potential of less than about $0.916 \mathrm{~V}$ and an $\mathrm{N}$ of 5.5 is evidently a forbidden $\mathrm{E}, \mathrm{N}$ combination. Equation 32 can be mathematically satisfied at $\mathrm{N}=5.5$ by $\mathrm{M}=1$. At this $\mathrm{N}$, $\mathrm{M}$ combination, $\mathrm{H}=0$. But this is also impossible, for the acidity of any 
plutonium solution in water cannot be zero, although it may be a very low value as in alkaline solutions. Evidently $(0.916 \mathrm{~V}, 5.5)$ is also a forbidden $\mathrm{E}, \mathrm{N}$ combination. However, this value must lie on the boundary, for any value of $M$ greater than unity gives a reasonable value for $\mathrm{H}$, and therefore corresponds to a tolerable $\mathrm{E}, \mathrm{N}$ combination. ${ }^{7}, 16$ When $\mathrm{N}=3.5$, Equation $31 \mathrm{~b}$ becomes

$$
\mathrm{H}^{4}=\frac{1.5 \mathrm{M}^{8}+2.5 \mathrm{M}^{3}}{(12.5)\left(10^{4}\right)-(0.95)\left(10^{4}\right)(\mathrm{M})} \text {. }
$$

Again, $H$ may not be zero or negative or infinity. Hence $M$ may not be larger than about 13.1. This corresponds to a potential of about 0.982 $V$, within the accuracy of the numerical constants in Equation 31. Hence, al1 values of $M$ greater than about 13.1 and a11 values of the potential greater than about $0.982 \mathrm{~V}$ are forbidden combinations with $\mathrm{N}=3.5$. It may also be observed from Equation $31 \mathrm{a}$ and $\mathrm{b}$ that for the interval between 4.0 and $5.0(4 \leq \mathrm{N} \leq 5)$ all values of $H$ are tolerable, and there is no value for $M$ which is forbidden. The formal potential of the $\mathrm{PuO}_{2}^{2+} / \mathrm{PuO}_{2}^{+}$couple has been taken as about $0.916 \mathrm{~V}$. Sometimes other numerical values, such as about $0.913 \mathrm{~V}$, are given as this formal potential value. 


\section{GENERALIZED CHARACTERISTIC EQUATIONS}

Recently, the possibility of representing much of the aqueous chemistries of uranium, neptunium, plutonium and perhaps americium by a single cubic equation has been suggested? ${ }^{7,9}$ An equation which represents an element in some of its aqueous reactions has been called a "characteristic equation". Such characteristic equations as have been suggested heretofore have required a given, fixed equilibrium acidity. Since actinide elements in their disproportionation reactions can change the solution acidity, the determination of actinide valence state distributions in terms of a given, fixed equilibrium acidity will occasionally be found artificial and restrictive. Moreover, if the concept of the characteristic equation is to be worthy, it should be sufficiently flexible to accommodate such intrinsic properties of elements as self-induced acidity changes. It is therefore a purpose of this section to demonstrate an equation for plutonium, the zero of which accounts for valence state adjustments and the new acidity produced by such adjustments. The final valence state distribution and acidity as found by this equation are calculated in terms of the parameters of plutonium average oxidation number and initial solution acidity. Hence, this section demonstrates one method of generalizing the characteristic equation concept. It is also a purpose of this section to illustrate how this generalized characteristic equation can be used by presenting an example of how this equation might be programmed. There may be better methods of generalizing a characteristic equation and better methods of rendering an equation to computing machinery than the methods illustrated here.

It may be recalled that the characteristic equation proposed for plutonium took the following form

$$
\begin{aligned}
& (\mathrm{AW})\left(\mathrm{K}_{2}^{2} / \mathrm{K}_{1}\right)(3-\mathrm{N})\left(\mathrm{H}^{4}\right)+(\mathrm{AX})\left(\mathrm{K}_{2} / \mathrm{K}_{1}\right)(4-\mathrm{N})\left(\mathrm{H}^{4}\right) \mathrm{M}+ \\
& (\mathrm{AY})(5-\mathrm{N}) \mathrm{M}^{3}+(\mathrm{AZ})(6-\mathrm{N}) \mathrm{M}^{3}=0
\end{aligned}
$$

when not expressed in terms of logarithms. In this equation, AW, AX, $\mathrm{AY}$, and $\mathrm{AZ}$ are alpha coefficients for trivalent, tetravalent, pentavalent, and hexavalent plutonium, respectively; $K_{1}$ and $K_{2}$ are about $(6.97)\left(10^{-4}\right)$ and $(13.2) ; \mathrm{H}$ is the equilibrium acidity; $\mathrm{N}$ is the average oxidation number; and $M$ is the ratio of ionic (uncomplexed) 
hexavalent plutonium to ionic (uncomplexed) pentavalent plutonium. This equation may be solved for $\mathrm{H}^{4}$

$$
\mathrm{H}^{4}=\frac{(\mathrm{N}-6)(\mathrm{AZ})\left(\mathrm{M}^{3}\right)+(\mathrm{N}-5)(\mathrm{AY})\left(\mathrm{M}^{2}\right)}{(\mathrm{AW})(3-\mathrm{N})\left(\mathrm{K}_{2}^{2} / \mathrm{K}_{1}\right)+(\mathrm{AX})(4-\mathrm{N})\left(\mathrm{K}_{2} / \mathrm{K}_{1}\right)(\mathrm{M})}
$$

and the fourth root of Equation 35 is one measure of the solution equilibrium acidity. Also, the final equilibrium acidity of a plutonium solution is

$$
\mathrm{HF}=\mathrm{HO}-4(\mathrm{TM})(\mathrm{YI}+\mathrm{ZI}-\mathrm{TO})-\mathrm{TM}(\mathrm{XH}-\mathrm{PH})
$$

where $\mathrm{HF}$ is the final acidity, $\mathrm{HO}$ is the original acidity, TM is the total molarity of all of the plutonium in the solution, YI and ZI are the initial fractions of pentavalent and hexavalent plutonium, TO is the fraction of oxygen bearing ions at equilibrium [i.e., the equilibrium fractions of $\mathrm{Pu}(\mathrm{V})$ and $\mathrm{Pu}(\mathrm{VI})$ taken together], $\mathrm{XH}$ is the initial fraction of $\mathrm{PuOH}^{3+}$, and $\mathrm{PH}$ is the equilibrium fraction of this species. It is also true that the total amount of plutonium in solution is the sum of soluble trivalent, tetravalent, pentavalent, and hexavalent plutonium, i.e., the sum of Equations 17-20. This sum is relative to ionic (uncomplexed) pentavalent plutonium taken as unity. Hence

$$
\mathrm{TO}=\frac{\mathrm{AY}+(\mathrm{AZ})(\mathrm{M})}{\Sigma \mathrm{Pu}}
$$

where "¿Su" represents the sum of the right hand members of Equations 17-20. But at equilibrium, the acidity as calculated by Equations 35 and 36 must be equal. Hence, a function of one variable which may be solved for the value of this variable under the condition of equilibrium is

$$
\mathrm{G}=\mathrm{H}-\mathrm{HF}=\mathrm{O}
$$

Equation 38 is one example of a generalized characteristic equation for plutonium.

For purposes of adaptation to computing machinery, a FOCAL language program may take several forms. Not necessarily the best form is to resolve Equation 35 so that

$$
\frac{\mathrm{H}^{4} \mathrm{~K}_{2}}{\mathrm{MK}_{1}}=\frac{(\mathrm{N}-5)(\mathrm{AY})(\mathrm{M})+(\mathrm{N}-6)(\mathrm{AZ})\left(\mathrm{M}^{2}\right)}{(\mathrm{AW})\left(\mathrm{K}_{2}\right)(3-\mathrm{N})+(\mathrm{AX})(4-\mathrm{N}) \mathrm{M}}=\frac{\mathrm{Q} 1}{\mathrm{Q} 2}
$$

then $\Sigma \mathrm{Pu}$ becomes

$$
\frac{\mathrm{H}^{4} \mathrm{~K}_{2}}{\mathrm{~K}_{1} \mathrm{M}}\left[\frac{(\mathrm{AW}) \mathrm{K}_{2}}{\mathrm{M}}+\mathrm{AX}\right]+\mathrm{AY}+(\mathrm{AZ})(\mathrm{M})=\Sigma \mathrm{Pu}
$$

or

$$
\frac{\mathrm{Q} 1}{\mathrm{Q} 2}\left[\frac{(\mathrm{AW}) \mathrm{K}_{2}}{\mathrm{M}}+\mathrm{AX}\right]+\mathrm{AY}+(\mathrm{AZ})(\mathrm{M})=\Sigma \mathrm{Pu}
$$


and

$$
\mathrm{PH}=\left(\frac{\mathrm{KH}}{\mathrm{H}}\right)\left(\frac{\mathrm{Q} 1}{\mathrm{Q} 2}\right) \quad\left(\frac{1}{\Sigma \mathrm{Pu}}\right)
$$

where

$$
\mathrm{KH}=\frac{\left[\mathrm{PuOH}^{3+}\right]\left[\mathrm{H}^{+}\right]}{\left[\mathrm{Pu}^{4+}\right]} .
$$

A numerical method which finds that $M$ value which allows Equation 38 to be zero or arbitrarily close to zero thus provides a method of empirically solving Equation 38. Of course, only positive values of $\mathrm{H}$ and $\mathrm{HF}$ are tolerable, and these are two conditions on the solution.

As is often the case with numerical methods, the searching routine is very important. In the case of the program shown in Table 5, the search is divided into three parts: a method for $\mathrm{K}<4$, a method for $N 5$, and a method for $4 \leq \mathrm{N} \leq 5$. In the last case, the limit of the search is set at $1 E+12$. This limit may be extreme, and may be decreased, for example to $1 \mathrm{E}+08$, with a consequent decrease in computing time, if it is certain that $M$ will not be greater than $1 E+08$.

Conversely, if $M$ is greater than $1 E+12$, this limit, given in step 2.10, may be increased. The searching constant, denoted " $P$ " at step 1.32 in Table 5 is set at $P=3$, a value which is by no means necessarily the value of choice. Other values of $\mathrm{P}$ might be $1.1,2,5,10,30$, $50,1.5$, or even 1.05. The constant " $P$ " is used to search the region of $M$ guesses which begins at $1 \mathrm{E}+12$ for $4 \leq \mathrm{N} \leq 5$. In some cases, such as when the initial or final acidity assumes low values (below about $0.1 \mathrm{M}$ ) it may happen that the value of Equation 38 will not appear to change sign as the range is searched with "P". This may occur when the function crosses the $C$ axis (where $C$ is a guess for $M$ ) an even number of times within $C$ and the product of $P$ and $C$ (PC). A typical case of this is shown in Figure 2. The value of Equation 38, denoted "G", is positive in this case only between the narrow limits of $\mathrm{C} 1.3$ to $\mathrm{C} \sim 2.1$. Above $\mathrm{C} \sim 2.1$ and below $\mathrm{C} \sim 1.3$, the value of Equation 38 is negative. Hence, a guess of $\mathrm{C}=1$ and $\mathrm{C}=3$ would show only negative values of $G$. The next guess for $C$ would be $C=0.333$. Hence, with $P=3$, the correct root has been missed and is not likely to be found with $\mathrm{P}=3$ unless the limit of the search is changed or, more practically, unless the value of " $P$ " is changed. The problem in Figure 2 can be solved by changing " $P$ " to $P=1.1$ or $P=1.05$, but if the scan must start at $1 \mathrm{E}+12$, this will take a very long time. Hence, neither the limit of the guessing range $(1 \mathrm{E}+12)$ nor the value of the scanning constant (3) are necessarily optimum at their present values. When $\mathbb{N}<4$ and $\$ 5$, an upper and lower limit may be placed upon $M$, by virtue of the forbidden nature of certain $\mathrm{N}, \mathrm{M}$ combinations. For example, when $\mathrm{N}=5.5$, the value of $\mathrm{M}$ cannot be less than unity, but values greater than unity are possible (complexation neglected).

There are many checks on the consistency and accuracy of the program answer, printed as a new valence state distribution and new acidity. 
The first of these is mere inspection of the answer to ascertain that the numbers are at least reasonable. The program should not lead to a negative value of the acidity, or a value which is beyond reasonable expectation, such as one million molar. In this connection, the program prints the results of two simple tests: the difference between the average oxidation numbers of the initial and final valence state distributions and the difference between the acidity values as calculated by Equations 35 and 36 , i.e., the value of Equation 38 . Both differences should be small, i.e., preferably less than about 0.001 , although for diverse purposes, diverse levels of accuracy may suffice. A low level of accuracy is most often caused by an incorrect number of bisection iterations. By increasing the iteration number, or perhaps by changing the value of "P" or some other constant, it is sometimes possible to improve the answer. Answers may be completely missed by any condition which narrows the interval between function sign changes. Such conditions may include low initial or final acidities, large alpha coefficients, values of $\mathrm{N}$ near their extreme values, large values of TM. Fortunately, such conditions are sometimes the ones which, from the point of view of the experimentalist, would appear bizarre or unlikely to arise. The program takes no account of precipitation or polymerization. Other tests for accuracy and consistency have been given formal acknowledgements in Section II. In cases where the computed acidity changes rapidly during operation of the program, the alpha coefficient for $\mathrm{Pu}(\mathrm{IV})$, denoted $\mathrm{AX}$, may also change considerably during computation. This is a complication to the bisection procedure, since the guessed values between which $M$ should lie are now themselves variables. The constants in Step 8.18 attempt to provide some compensation for this. When several attempts at changing the iteration number, and then the value of $P$ (and perhaps also the guess limit for $4 \leq \mathrm{N} \leq 5$ ) have failed, and when a trace of $M$ at paragraph eight indicates failure of the bisection procedure, then the values of the constants in Step 8.18 might be changed to good advantage. When a trace of $M$ at paragraph eight indicates that the approach of $M$ to its equilibrium value is very slow, it may be desirable to increase the iteration number or the values of the constants in step 8.18 from their present values of 1.03 to, for example, $1.05,1.1,1.2,1.5$, or 2.0 . It is not necessary that the values of these constants be identical. When the approach of the parameter $M$ to its presumed equilibrium value is erratic, then the values of the constants in step 8.18 may be too large and may be decreased, for example, to 1.01 or 1.001 . When this suggestion fails, the problem may frequently be solved by assigning zero to the value of $\mathrm{KH}$, and entering a fixed value for the alpha coefficient $\mathrm{AX}$ which is only a guess for the correct value of $\mathrm{AX}$, including hydrolysis, under the condition of the supposed equilibrium acidity. When the problem is solved with the guessed AX value, a new, better value of AX may be estimated from the calculated solution equilibrium acidity. This leads to a new value of the calculated solution equilibrium acidity which allows a still better guess for $A X$, and this procedure may be repeated a few times until the value of AX under the conditions of the solution equilibrium acidity and the guessed value of AX agree reasonably well. 
Sometimes, a good initial guess for $\mathrm{AX}$ is unity. In such manner can difficulties produced by an internally variable value of $A X$ sometimes be obviated. (The value of $\mathrm{AX}$ may be variable since $\mathrm{AX}$, the $\mathrm{Pu}$ (IV) alpha coefficient, is the sum of a fixed term, denoted "A4" in the program, and the acid dependent hydrolysis term $\mathrm{KH} / \mathrm{H}^{+}$which changes during computation.) Because paragraph eight contains some provision for correcting the guessed values of $M$ for a variable $P u(I V)$ alpha coefficient as well as the standard bisection procedure, it is sometimes necessary to iterate this paragraph a large number of times. Usually, 15-30 iterations are sufficient, but sometimes as many as one hundred are necessary. Occasionally, increasing the iteration number decreases the accuracy.

Another type of program failure deals with the nature of computing machinery. If $\mathrm{N}=4.0$ exactly, as with pure $\mathrm{Pu}(\mathrm{IV})$, the program should branch to paragraph 2. With some FOCAL languages it has branched to paragraph 9. Upon answering a request to type the value of $(\mathrm{N}-4)$, a small negative number resulted instead of the expected zero. Such roundoff errors may cause program failure, but the point of the program in Table 5 is merely to illustrate that generalized characteristic equations may form a useful adjunct to plutonium chemistry. of course, there are many ways by which the program in Table 5 might be modified to improve its usefulness. For example, there might on occasion be advantage in rewriting statement 4.16 as follows:

$$
4.16 \mathrm{SPH}=\left(\mathrm{K}_{2} / \mathrm{K}_{1}\right)(\mathrm{KH} / \mathrm{H})(1 / \mathrm{TP})\left(\mathrm{H}^{4} / \mathrm{C}\right) \text {. }
$$

Sometimes running the program in a language which carries 10 (or more) digit accuracy yields a more accurate answer (as judged by the printed tests) than a language which carries only 6 digit accuracy. This may happen near the extremes of $\mathrm{N}$, for example. 


\section{POTENTIAL VALUES OF PLUTONIUM SOLUTIONS}

The potentials of plutonium solutions, it has been remarked elsewhere, ${ }^{16}$ may be any values whatsoever when $N=4.0$ or 5.0 exactly. It may be asked how this is possible, since a large potential in solutions of tetravalent flutonium, for example, may oxidize tetravalent plutonium to hexavalent plutonium:

$$
\mathrm{Pu}^{4+}+2 \mathrm{H}_{2} \mathrm{O}=\mathrm{PuO}_{2}^{2+}+4 \mathrm{H}^{+}+2 \mathrm{e} .
$$

But however large the potential which is applied, either chemically or electrolytically, there will always be some value of $\mathrm{H}^{+}$, the equilibrium acidity, which will be large enough to prevent such oxidation. In part, this may be understood as follows. Consider the traditional representation of the disproportionation of tetravalent plutonium in strongly acidic solutions:

$$
3 \mathrm{Pu}^{4+}+2 \mathrm{H}_{2} \mathrm{O}=2 \mathrm{Pu}^{3+}+\mathrm{PuO}_{2}^{2+}+4 \mathrm{H}^{+} .
$$

As the acidity increases, more and more of the plutonium will be distributed solely among the (III), (IV), and (VI) states, and less and less will be found in the pentavalent form. As the acidity increases, Equation 45 thus becomes a better and better representation of the disproportionation which occurs in the plutonium solution. But Equation 45 predicts that, whatever the extent of the disproportionation, the stoichiometry of the disproportionation is such that the ratio of hexavalent to trivalent plutonium is 0.5 . Hence, in high acidities, the potential of a solution of plutonium, with $\mathbb{N}=4.0$ exactly, may be approximated by

$$
E_{\text {solution }} \sim \mathrm{E}_{\mathrm{Z}, \mathrm{W}}+0.02 \log (0.5)+0.08 \log \left[\mathrm{H}^{+}\right] \cdot(46)
$$

Now, whatever the value of the solution potential, there will always be some value of the equilibrium acidity such that this potential value is just appropriate for $\mathrm{N}=4.0$, and hence no oxidation will occur. Similar arguments may be used for the reduction of tetravalent plutonium (but in low acidity in this case) and for plutonium at $N=5.0$. 
Acknowledgement: The author wishes to thank M. R. Hertz and C. J. Kershrer for their helpful suggestions on the radioactive battery and Leon Winslow of the Computer Sciences Department, Wright State University, Dayton, Ohio, for his helpful suggestions and discussions on techniques for estimating acidity changes in plutonium solutions. 


\section{REFERENCES}

1. G. L. Silver, Plutonium Disproportionation Reactions: Some Unresolved Problems, MLM-1807 (May 10, 1971), 68 pp.

2. G. L. Silver, Minor Problems in Aqueous Plutonium Chemistry, MLM2075 (October 1, 1973), 55 pp.

3. M. T. Beck, Chemistry of Complex Equilibria, Van Nostrand Reinhold Co., New York, 1970, Chapter 2.

4. J. N. Butler, Ionic Equilibrium, A Mathematical Approach, Addison Wesley Publishing Co., Reading, Mass., 1964, Chapter 12.

5. D. A. Costanzo, R. E. Biggers and J. T. Bell, J. Inorg. Nucl. Chem., 35, 609 (1973).

6. Mound Laboratory Isotopic Power Fuels Programs: April-June 1973, MLM-2080 (Sept. 7, 1973), pp. 44-46.

7. G. L. Silver, The Three Actinides Equilibrium Problem, MLM-2007 (March 6, 1973), 35 pp.

8. G. L. Silver, Aqueous Plutonium Chemistry: Some Minor Problems, MLM-1871 (May 26, 1972), 68 pp.

9. G. L. Silver, to be published in J. Inorg. Nucl. Chem. (1974).

10. G. Friedlander and J. Kennedy, Nuclear and Radiochemistry, John Wiley \& Sons, Inc., New York, 1955.

11. G. N. Huffman, Effective Alpha Activity of Plutonium-238 Dioxide Microspheres, MLM-1642 (April 1, 1969), 104 pp.

12. G. N. Huffman and C. J. Kershner, Nuclear Applications and Technology, 9 , 434-8 (1970).

13. G. L. Silver, Nature of the Steady State of Plutonium-238 in Dilute Nitric and Hydrochloric Acids, MLM-1709 (March 6, 1970), 14 pp.

14. G. L. Silver, U. S. Patent 3,492,160 (January 27, 1970). 
15. J. M. Cleveland, The Chemistry of Plutonium, Gordon and Breach Science Publishers, New York, 1970, Chapter 3.

16. G. L. Silver, Radiochem. Radioana1. Letters, 13 (1), 1 (1973). 
Table 1

LOGARITHMIC STATEMENT OF GENERAL PLUTONIUM EQUILIBRIUM PROBLEM

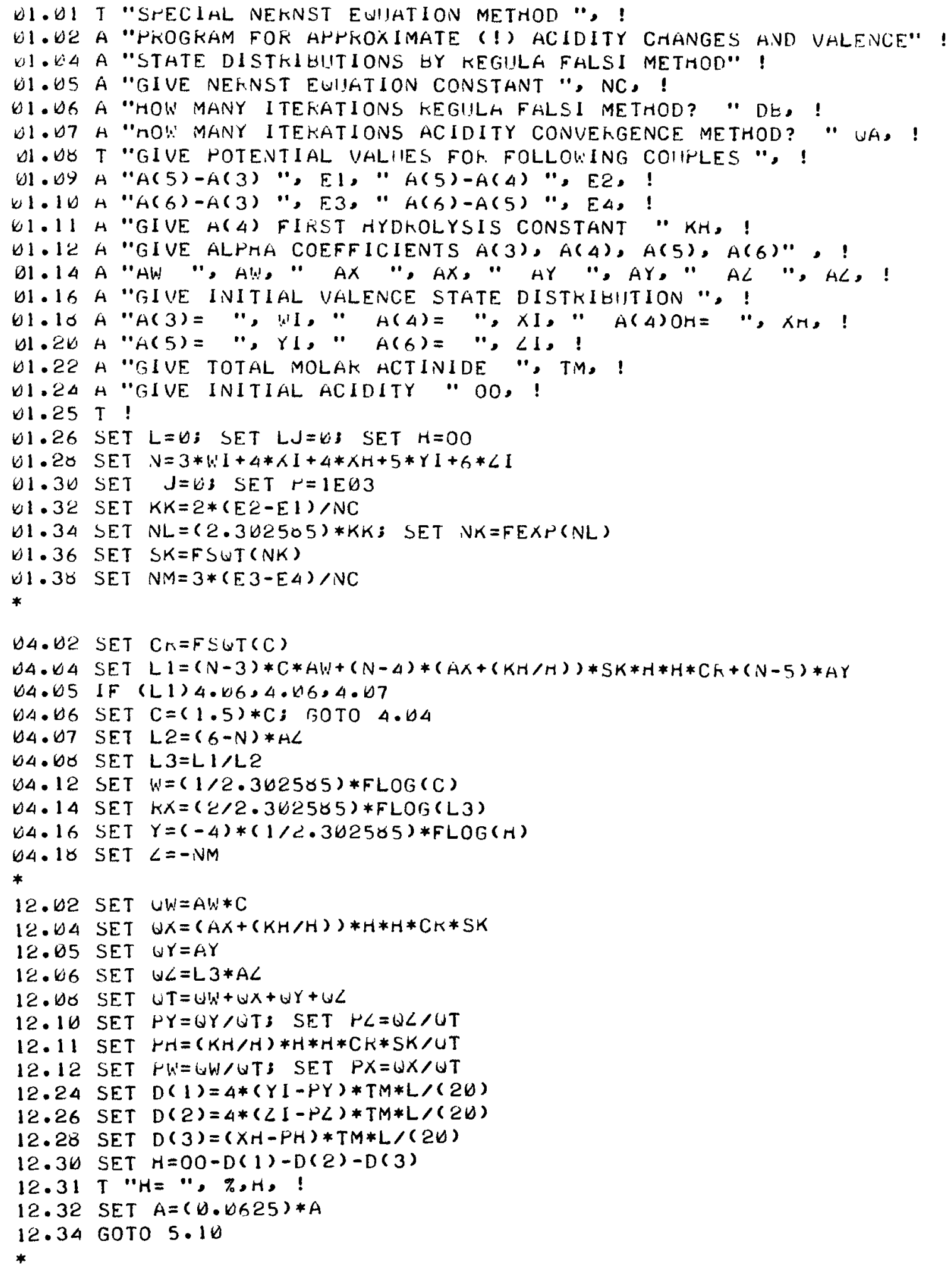


Table 2

APPROXIMATE ACIDITY CHANGES IN PLUTONIUM SOLUTIONS BY CHEBYSCHEV POLYNOMIALS

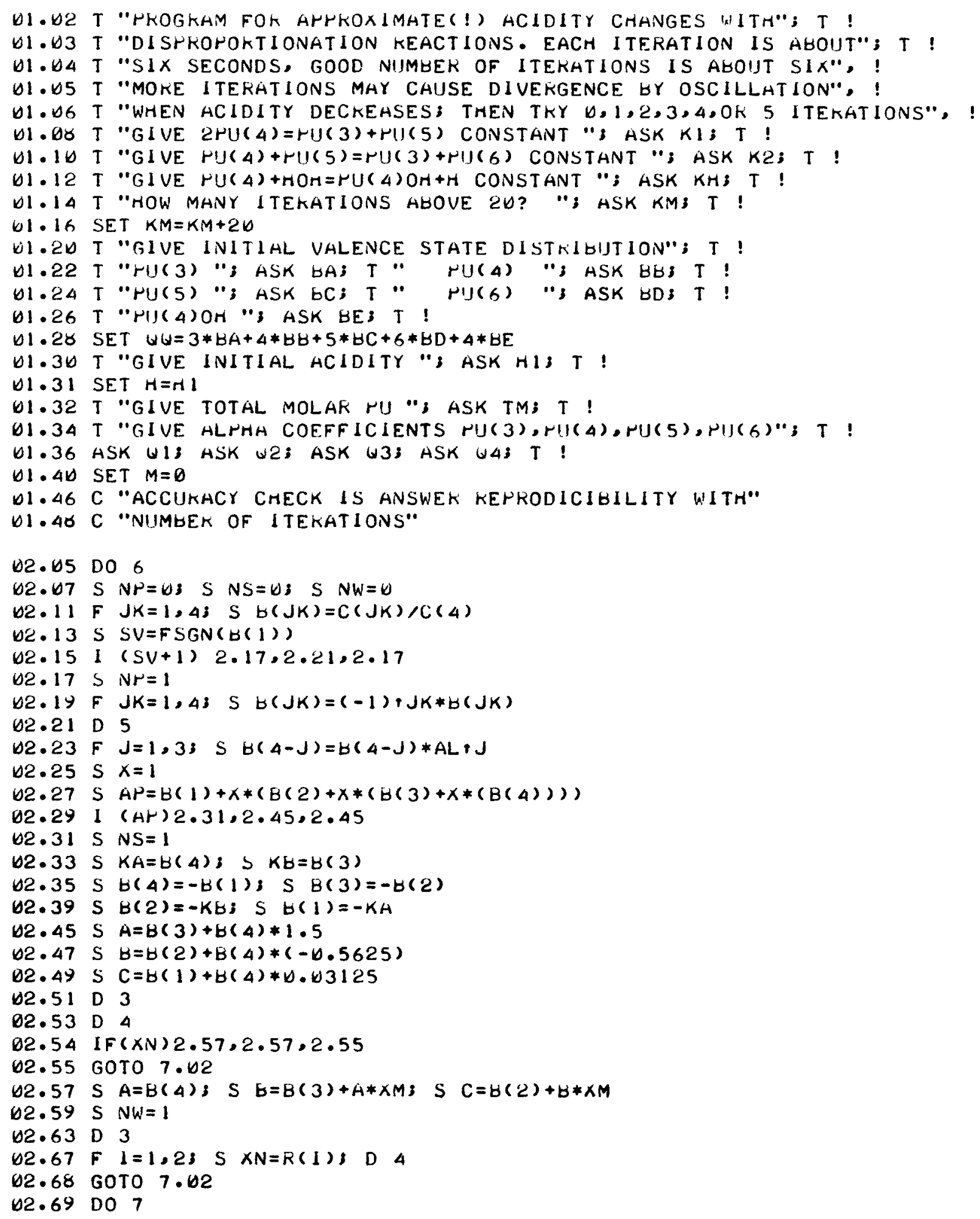




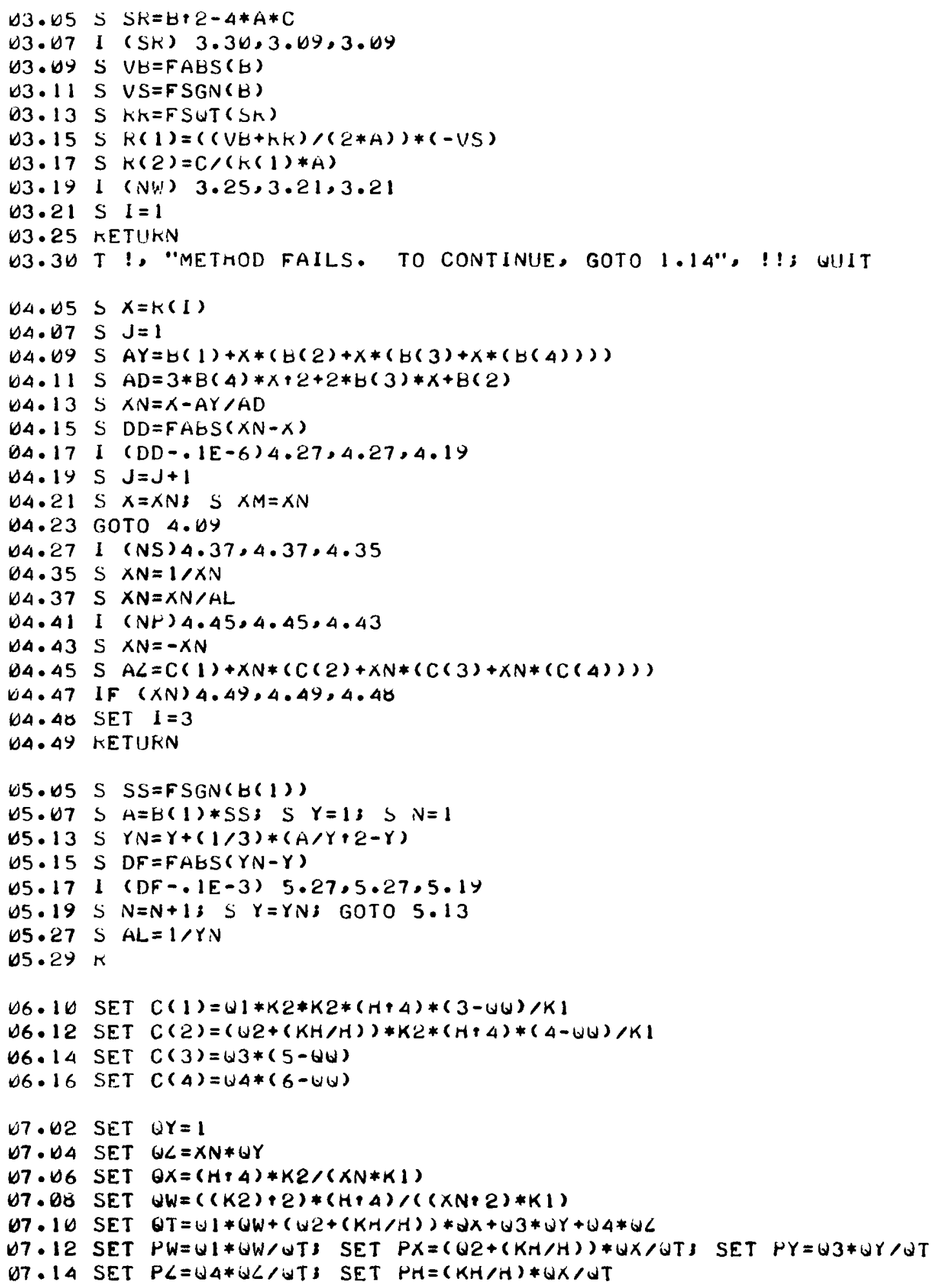


Table 2 (continued)

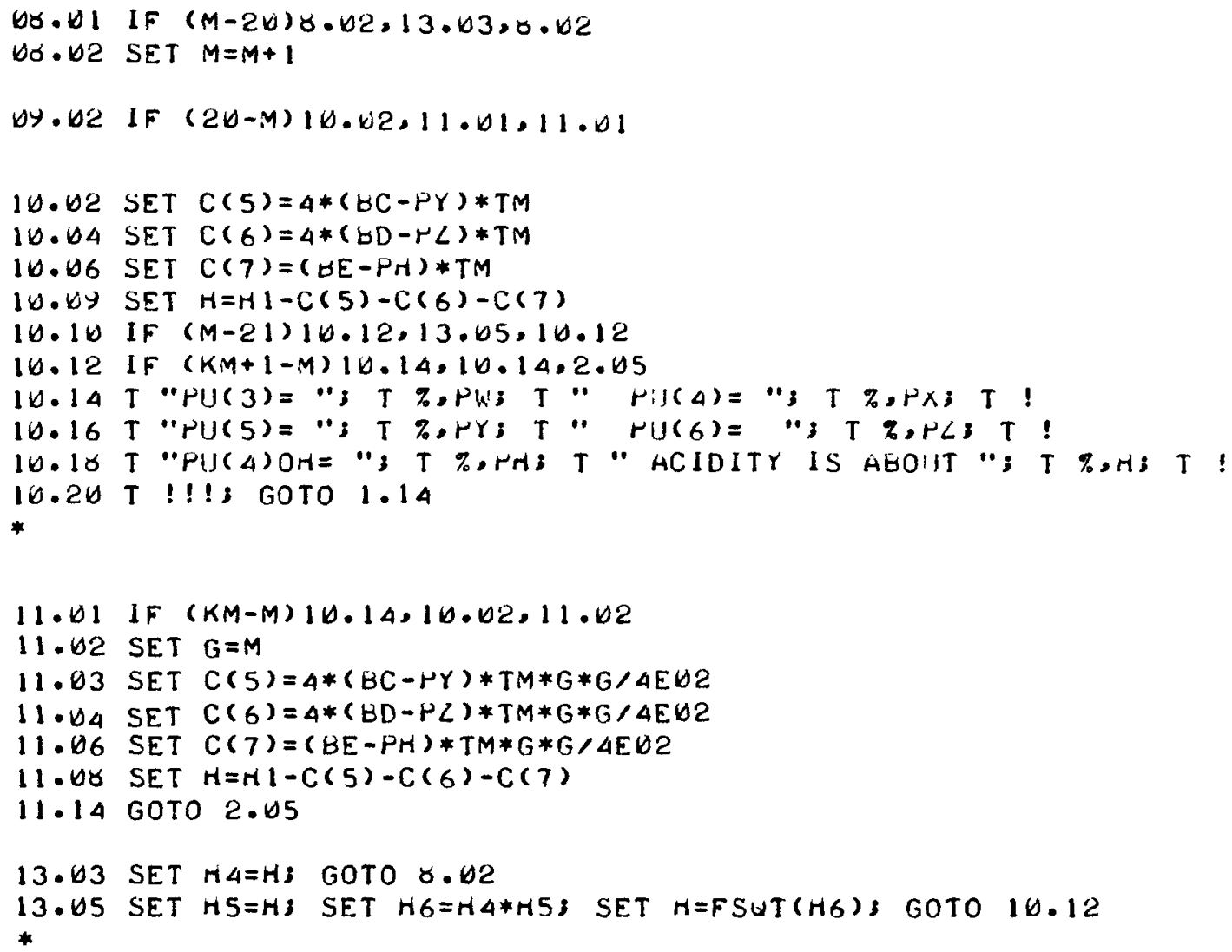


Table 3

VOLTAGES OF TWO PLUTONIUM-238 RADIATION CELLS

Cel1 非: Electrolyte - $2 \mathrm{M} \mathrm{HBr}, \mathrm{ca} .200 \mathrm{mg}$ of ${ }^{238} \mathrm{PuO}_{2}$ in Cathode, ca. $50 \mathrm{mg}$ of ${ }^{238} \mathrm{PuO}_{2}$ in Arode

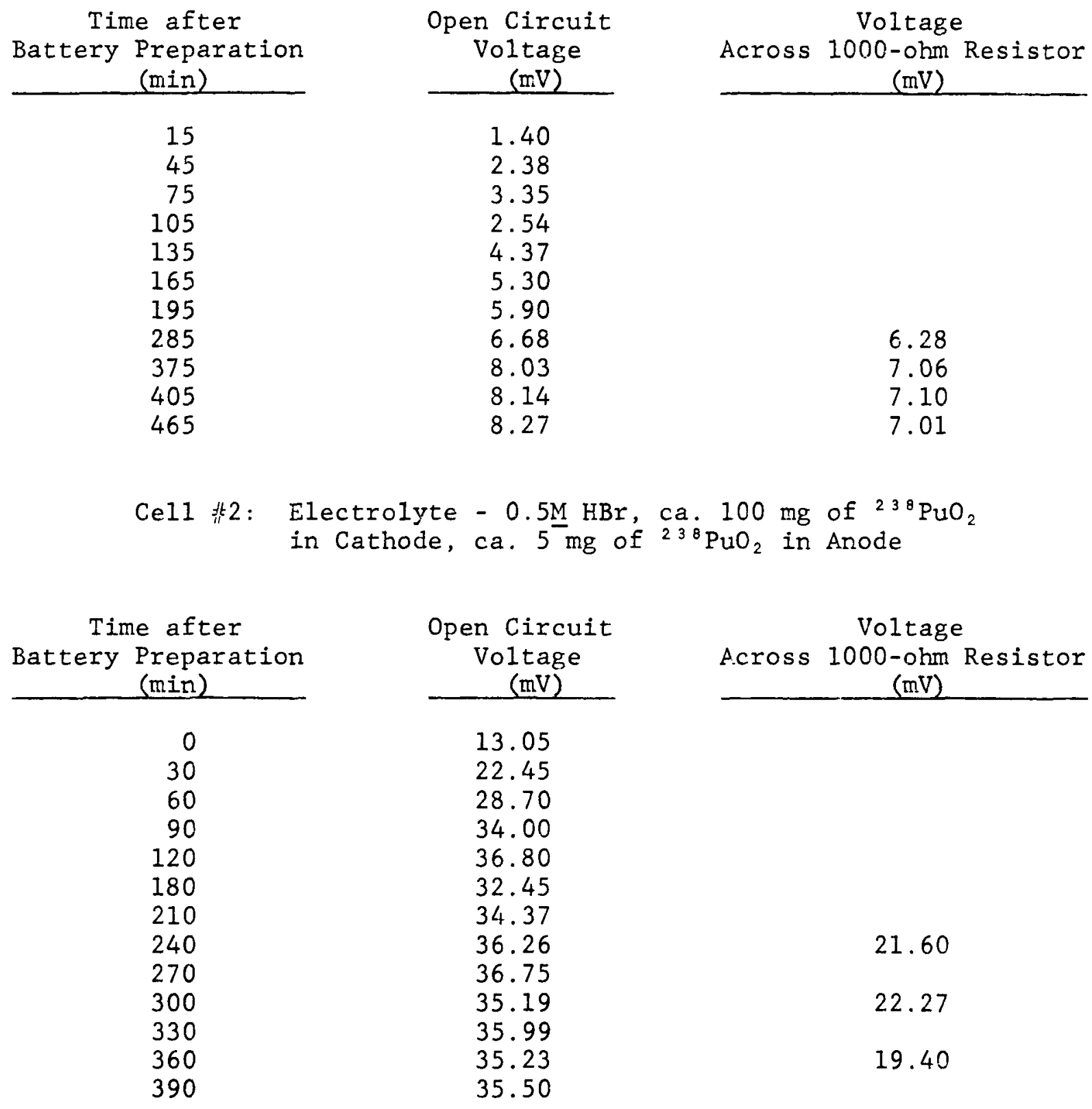

NOTE: $\quad{ }^{238} \mathrm{PuO}_{2}$ microspheres contained $80 \%$ plutonium-238 and $20 \%$ plutonium-239 
Table 4

THE IRON-PLUTONIUM REACTION

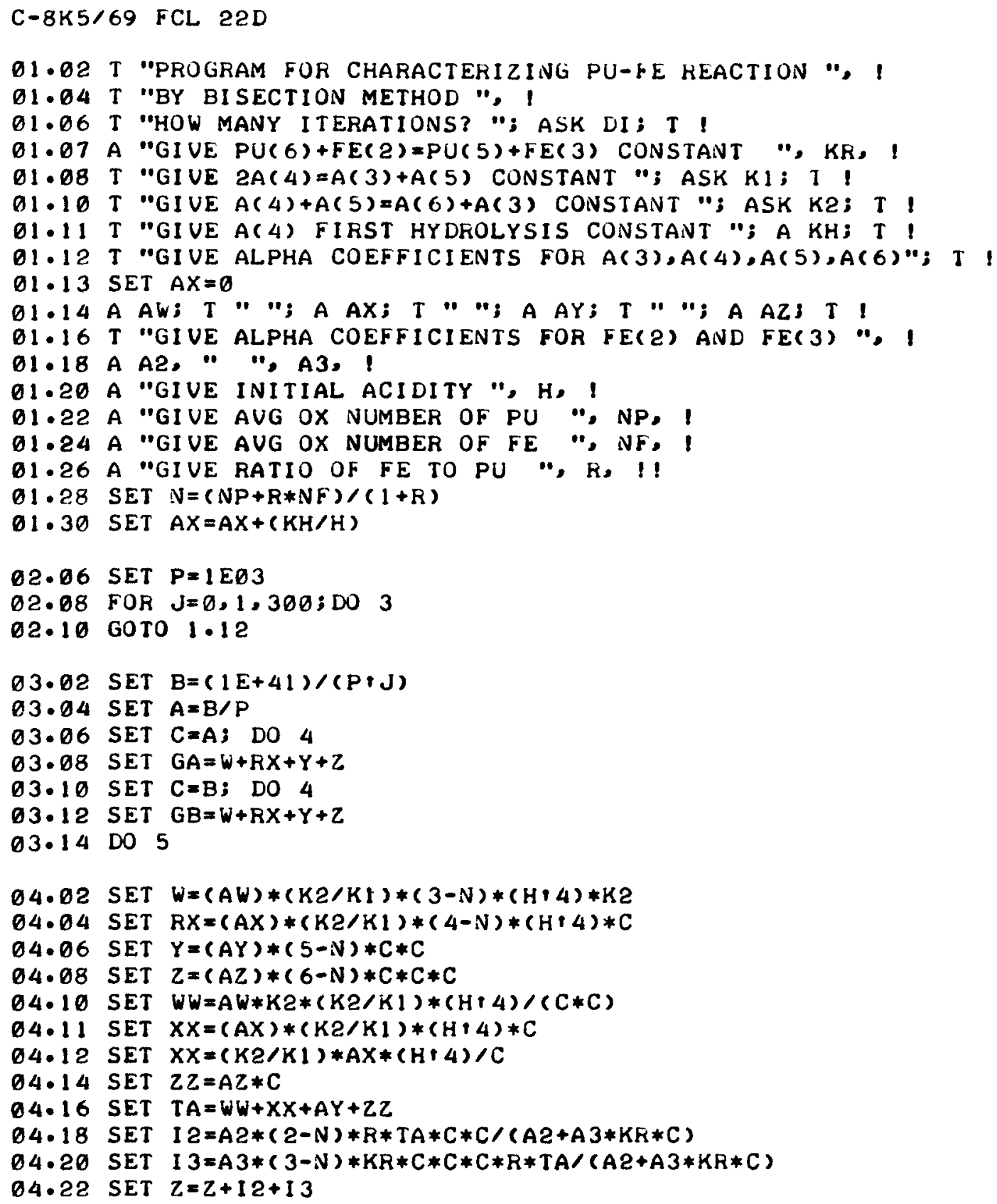


Table 4 (continued)

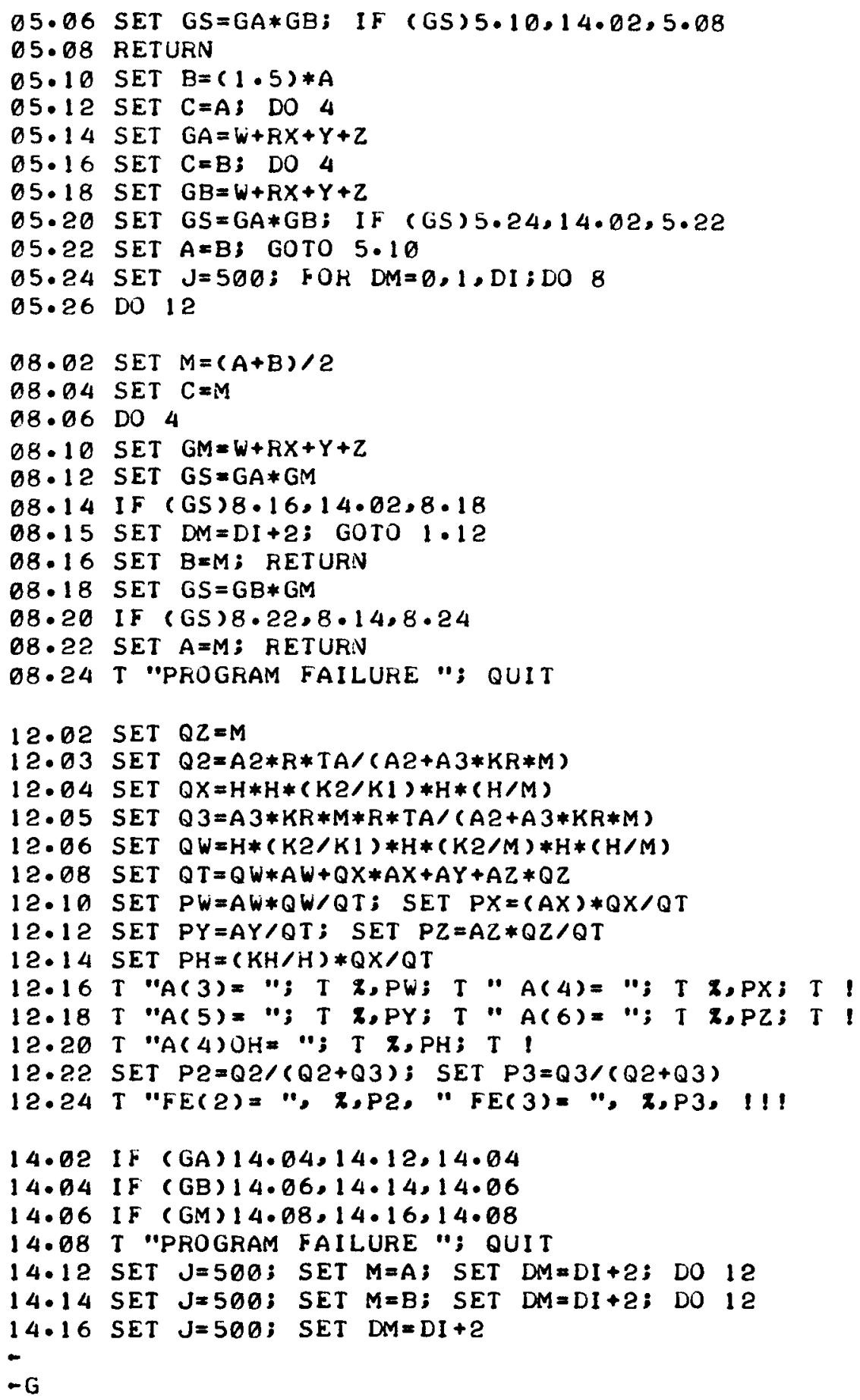




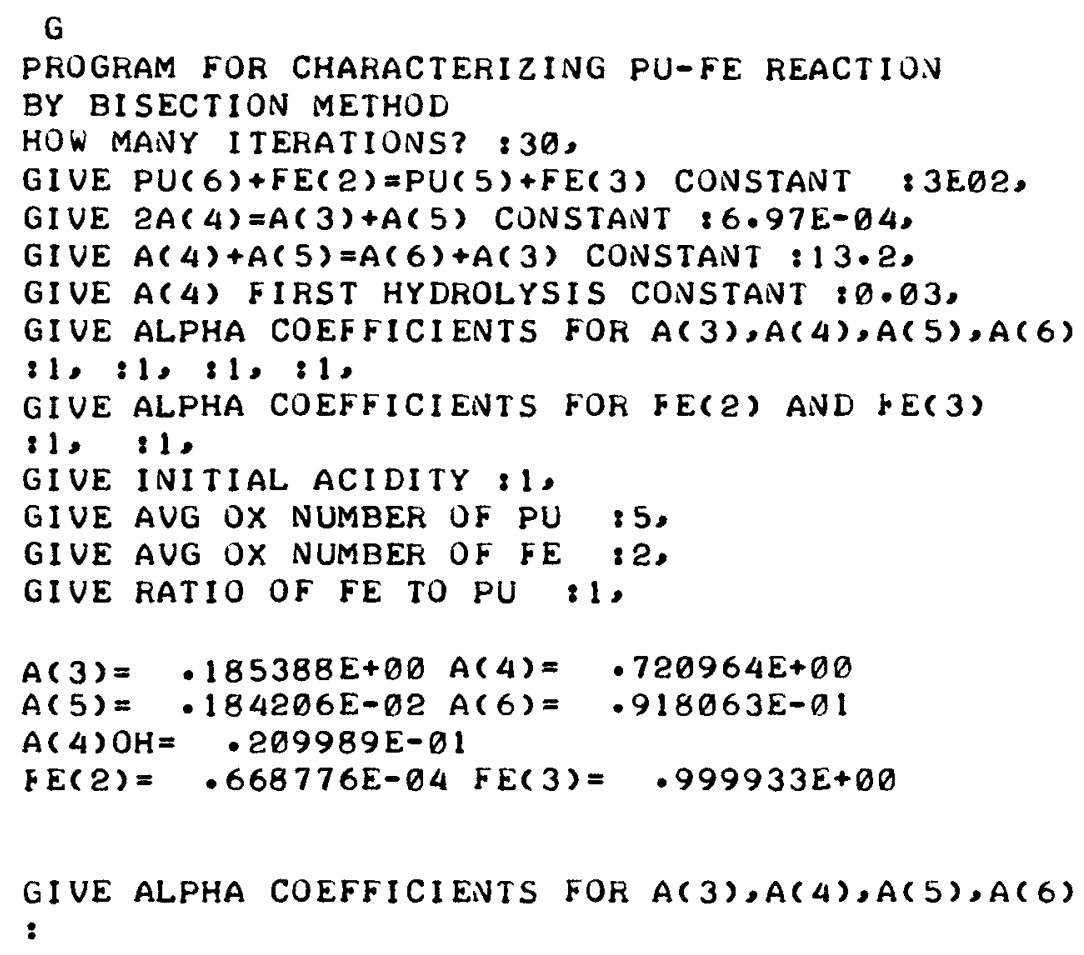


Table 5

ACIDITY CHANGES IN ACTINIDE SOLUTIONS: BISECTION ADAPTATION OF A GENERALIZED CHARACTERISTIC EQQUATION

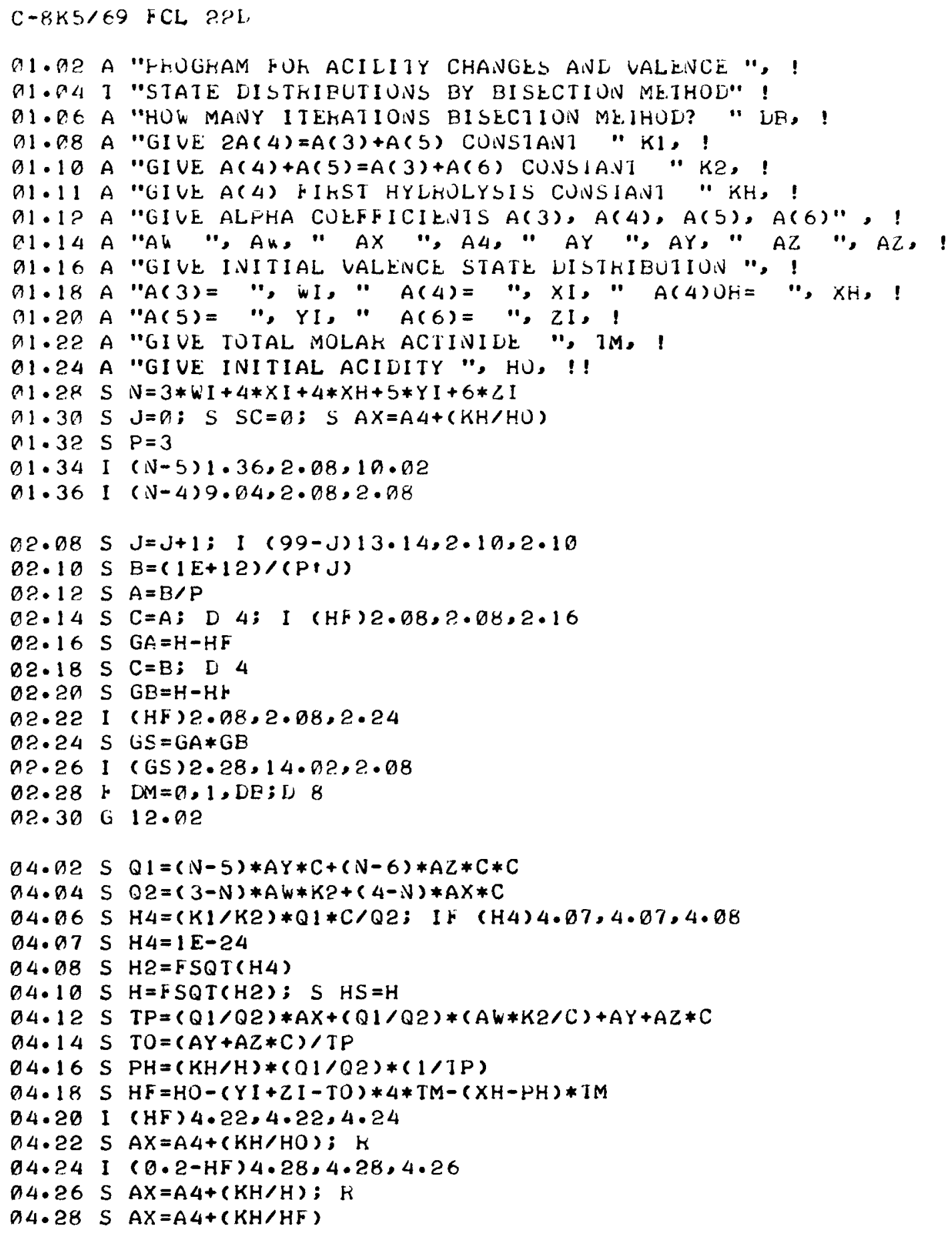


Table 5 (continued)

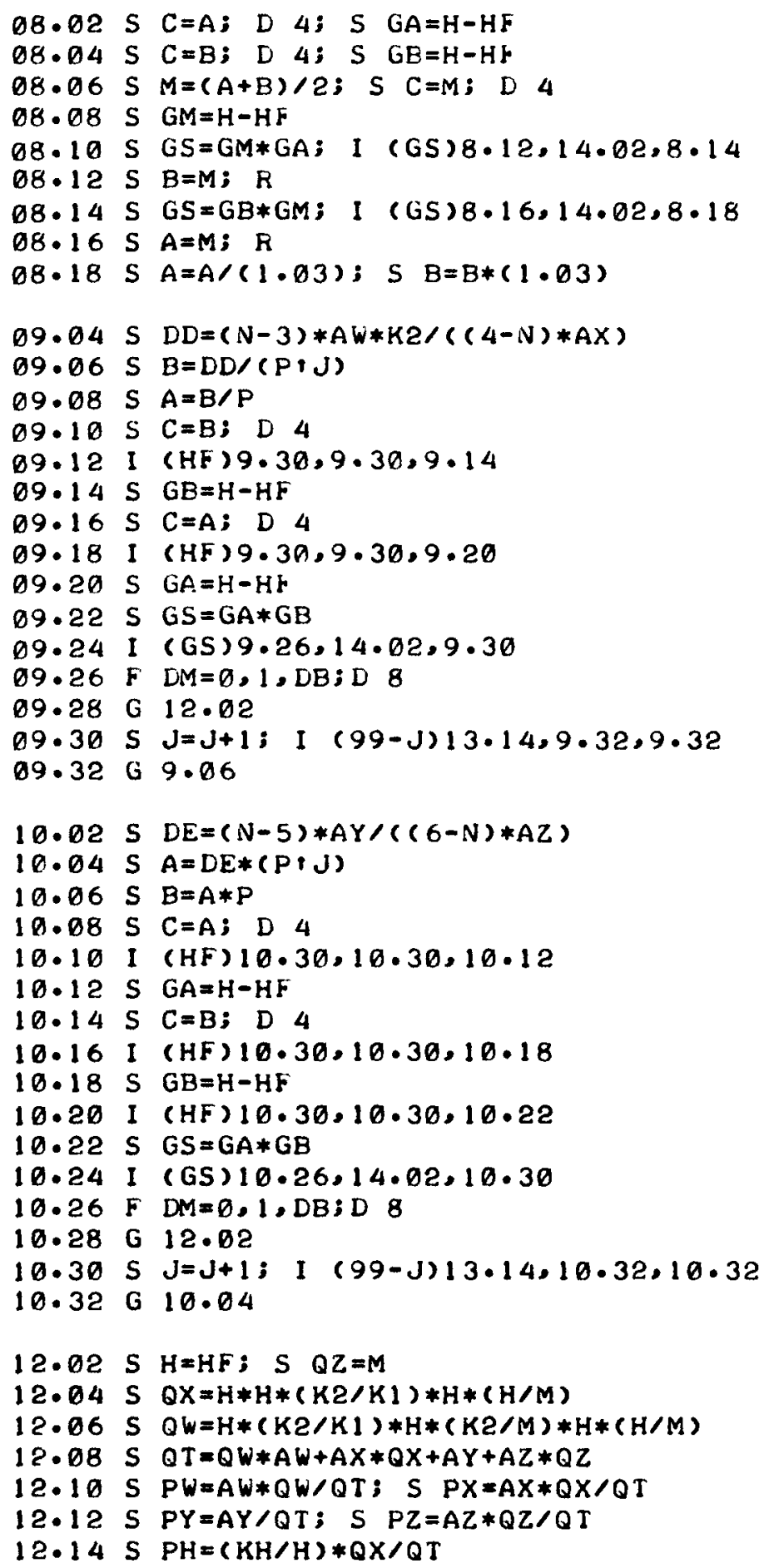




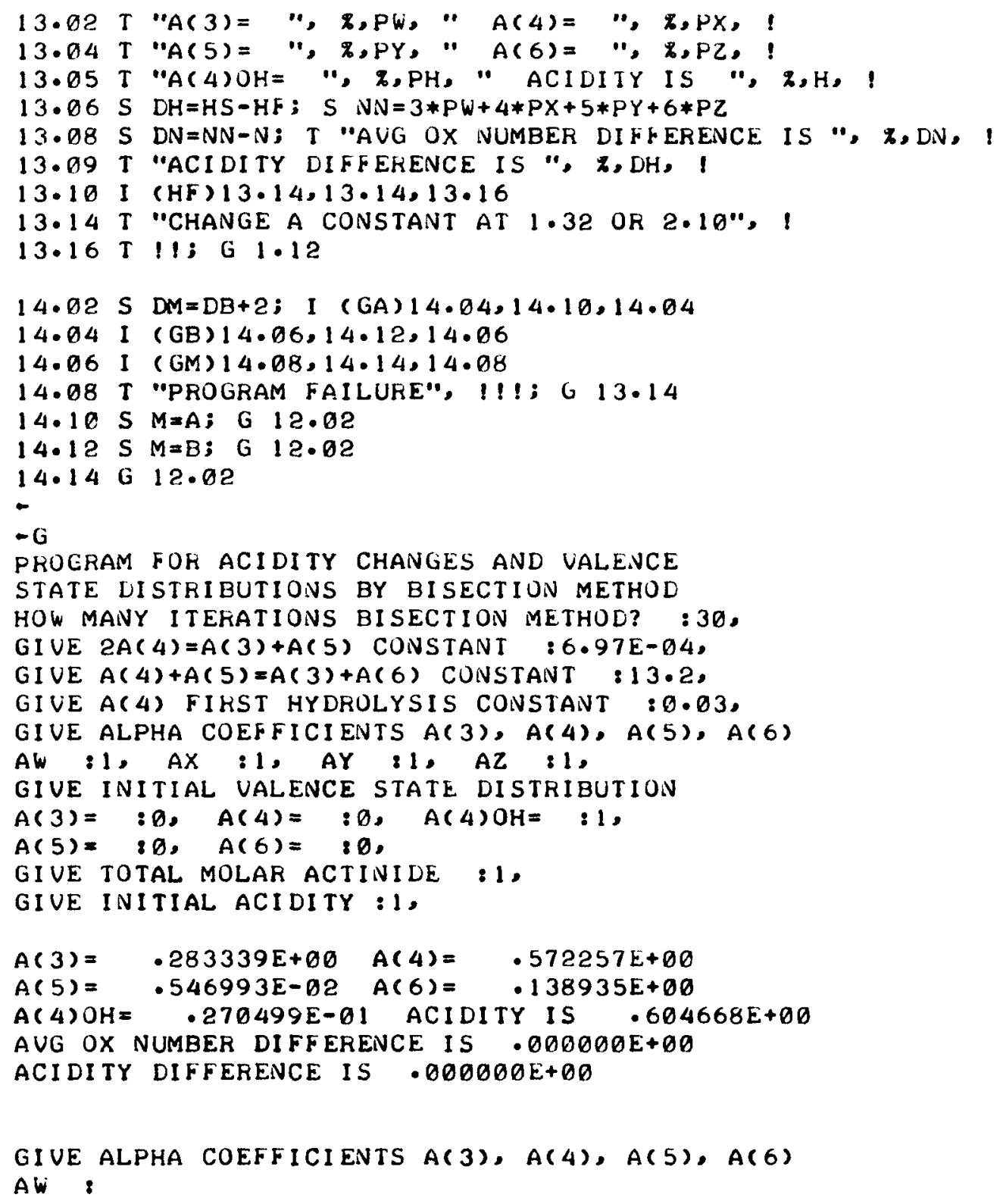


Table 6

GENERAL PLUTONIUM EQUILIBRIUM PROBLEM IN POTENTIAL AND AVERAGE OXIDATION NUNABER FORM

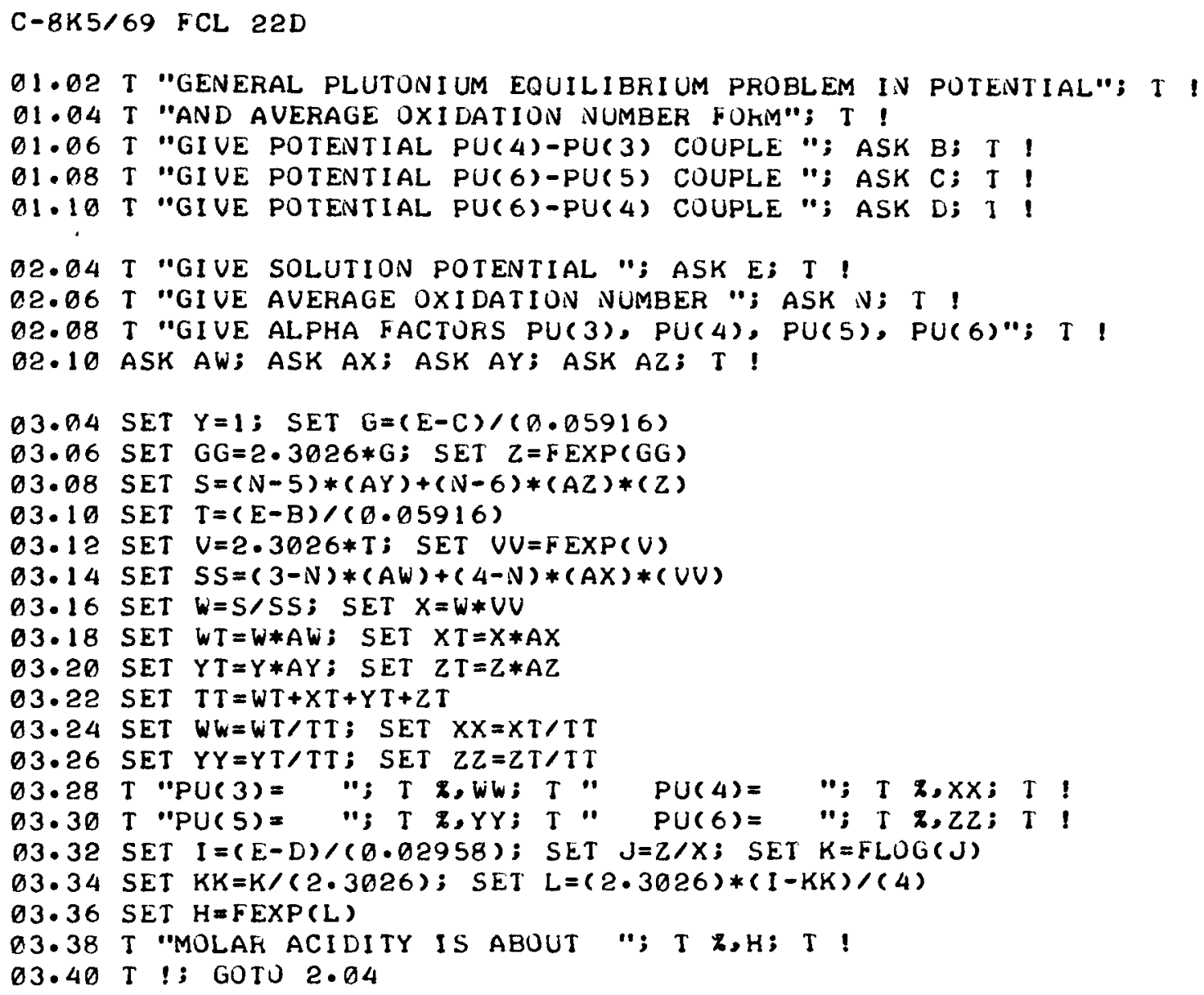




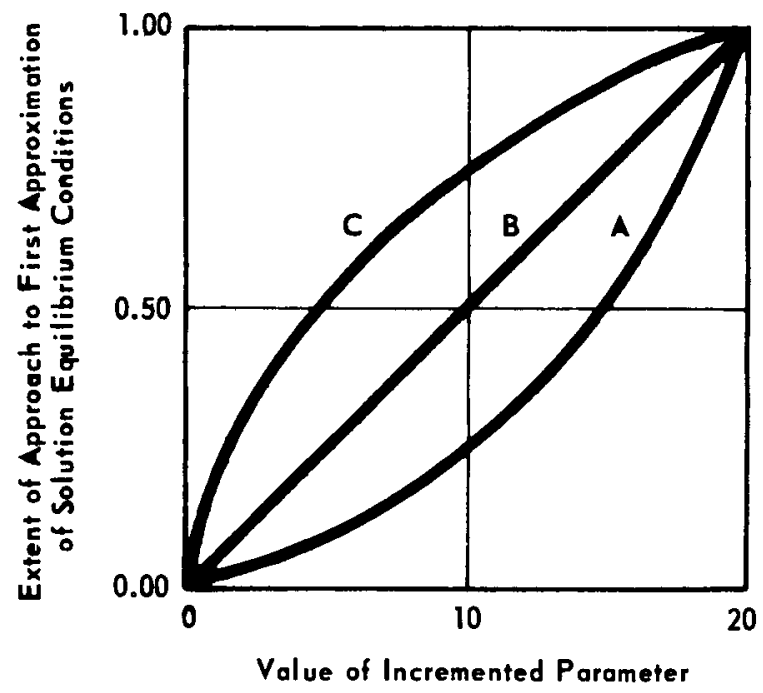

FIGURE 1 - Method of approach to first approximation of equilibrium acidity for three programs.

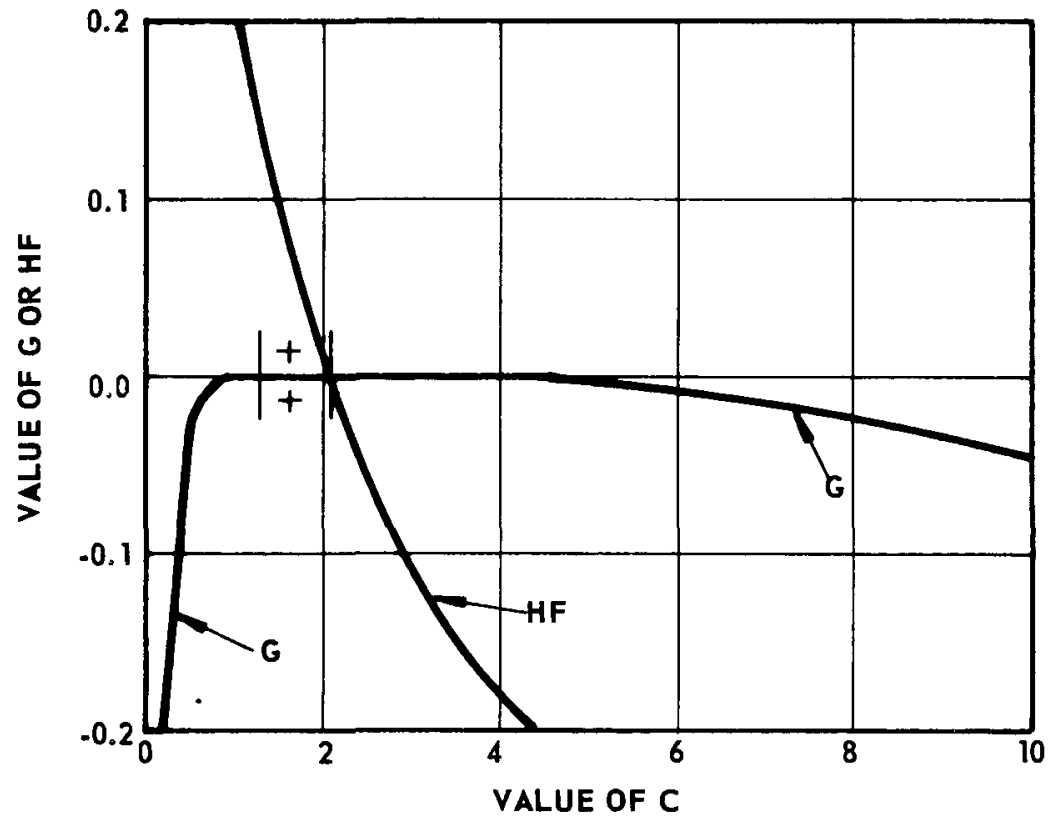

FIGURE 2 - Behavior of the final acidity $H F$ and the value of $G$ from Equation 38 for a selected Pu(V) test case. Region of positive $G$ values lies between small vertical lines. 